University of South Florida

DIGITAL COMMONS @ UNIVERSITY OF SOUTH FLORIDA
Digital Commons @ University of South Florida

$9-1-2015$

\title{
Flexible Public Transportation in Florida
}

CUTR

Follow this and additional works at: https://digitalcommons.usf.edu/cutr_nctr

\section{Recommended Citation}

"Flexible Public Transportation in Florida," National Center for Transit Research (NCTR) Report No. CUTRNCTR-RR-2012-04, Center for Urban Transportation Research, University of South Florida, 2015.

DOI: https://doi.org/10.5038/CUTR-NCTR-RR-2012-04

Available at: https://scholarcommons.usf.edu/cutr_nctr/97

This Technical Report is brought to you for free and open access by the National Center for Transit Research (NCTR) Archive (2000-2020) at Digital Commons @ University of South Florida. It has been accepted for inclusion in Research Reports by an authorized administrator of Digital Commons @ University of South Florida. For more information, please contact digitalcommons@usf.edu. 

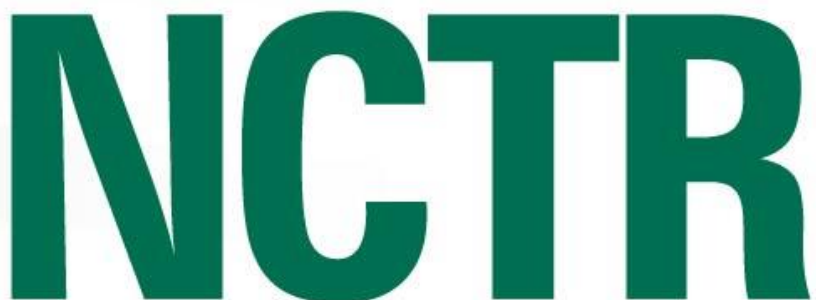

NATIONAL CENTER for TRANSIT RESEARCH

\section{Flexible Public Transportation Services in Florida}

FINAL REPORT

AUGUST 2013

PROJECT NO. BDK85 977-37

PREPARED FOR

Florida Department of Transportation

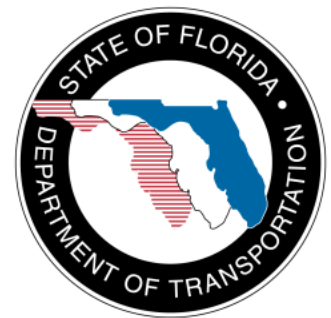




\section{Flexible Public Transportation Services in Florida}

\section{Final Report}

\section{Prepared for:}

Florida Department of Transportation

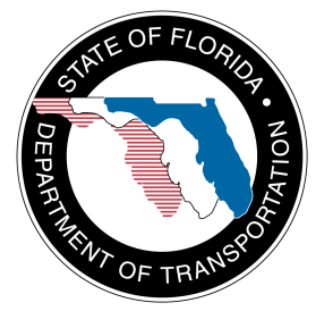

\section{Project Manager:}

Elizabeth Stutts

Florida Department of Transportation

Prepared by:

Jay A. Goodwill and Lisa Staes

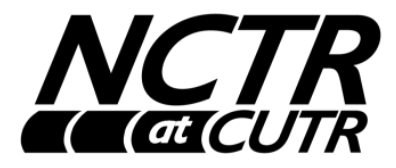

National Center for Transit Research

Center for Urban Transportation Research (CUTR)

University of South Florida

4202 East Fowler Avenue, CUT100

Tampa, Florida 33620-5375

August 2013

Project No. BDK85 977-37 


\section{DISCLAIMER}

The contents of this synthesis report reflect the views of the authors, who are responsible for the facts and the accuracy of the information presented herein. This document is disseminated under the sponsorship of the Department of Transportation University Transportation Centers Program and the Florida Department of Transportation, in the interest of information exchange. The U.S. Department of Transportation and the Florida Department of Transportation, assume no liability for the contents or use thereof.

The opinions, findings, and conclusions expressed in this publication are those of the authors and not necessarily those of the Florida Department of Transportation. 


\section{Metric Conversion}

\begin{tabular}{|c|c|c|c|c|}
\hline SYMBOL & $\begin{array}{c}\text { WHEN YOU } \\
\text { KNOW }\end{array}$ & MULTIPLY BY & TO FIND & SYMBOL \\
\hline \multicolumn{5}{|c|}{ LENGTH } \\
\hline in & inches & 25.4 & millimeters & $\mathrm{mm}$ \\
\hline ft & feet & 0.305 & meters & $\mathrm{m}$ \\
\hline yd & yards & 0.914 & meters & $\mathrm{m}$ \\
\hline mi & miles & 1.61 & kilometers & $\mathrm{km}$ \\
\hline \multicolumn{5}{|c|}{ VOLUME } \\
\hline floz & fluid ounces & 29.57 & milliliters & $\mathrm{mL}$ \\
\hline gal & gallons & 3.785 & liters & $\mathrm{L}$ \\
\hline $\mathrm{ft}^{3}$ & cubic feet & 0.028 & cubic meters & $\mathrm{m}^{3}$ \\
\hline$y^{3}$ & cubic yards & 0.765 & cubic meters & $\mathrm{m}^{3}$ \\
\hline \multicolumn{5}{|c|}{ NOTE: volumes greater than $1000 \mathrm{~L}$ shall be shown in $\mathrm{m}^{3}$} \\
\hline \multicolumn{5}{|c|}{ MASS } \\
\hline oz & ounces & 28.35 & grams & $\mathrm{g}$ \\
\hline lb & pounds & 0.454 & kilograms & $\mathrm{kg}$ \\
\hline $\mathbf{T}$ & short tons (2000 lb) & 0.907 & $\begin{array}{l}\text { megagrams } \\
\text { (or "metric } \\
\text { ton") }\end{array}$ & Mg (or "t") \\
\hline \multicolumn{5}{|c|}{ TEMPERATURE (exact degrees) } \\
\hline${ }^{\circ} \mathbf{F}$ & Fahrenheit & $\begin{array}{c}5(F-32) / 9 \\
\text { or }(F-32) / 1.8\end{array}$ & Celsius & ${ }^{\circ} \mathrm{C}$ \\
\hline
\end{tabular}




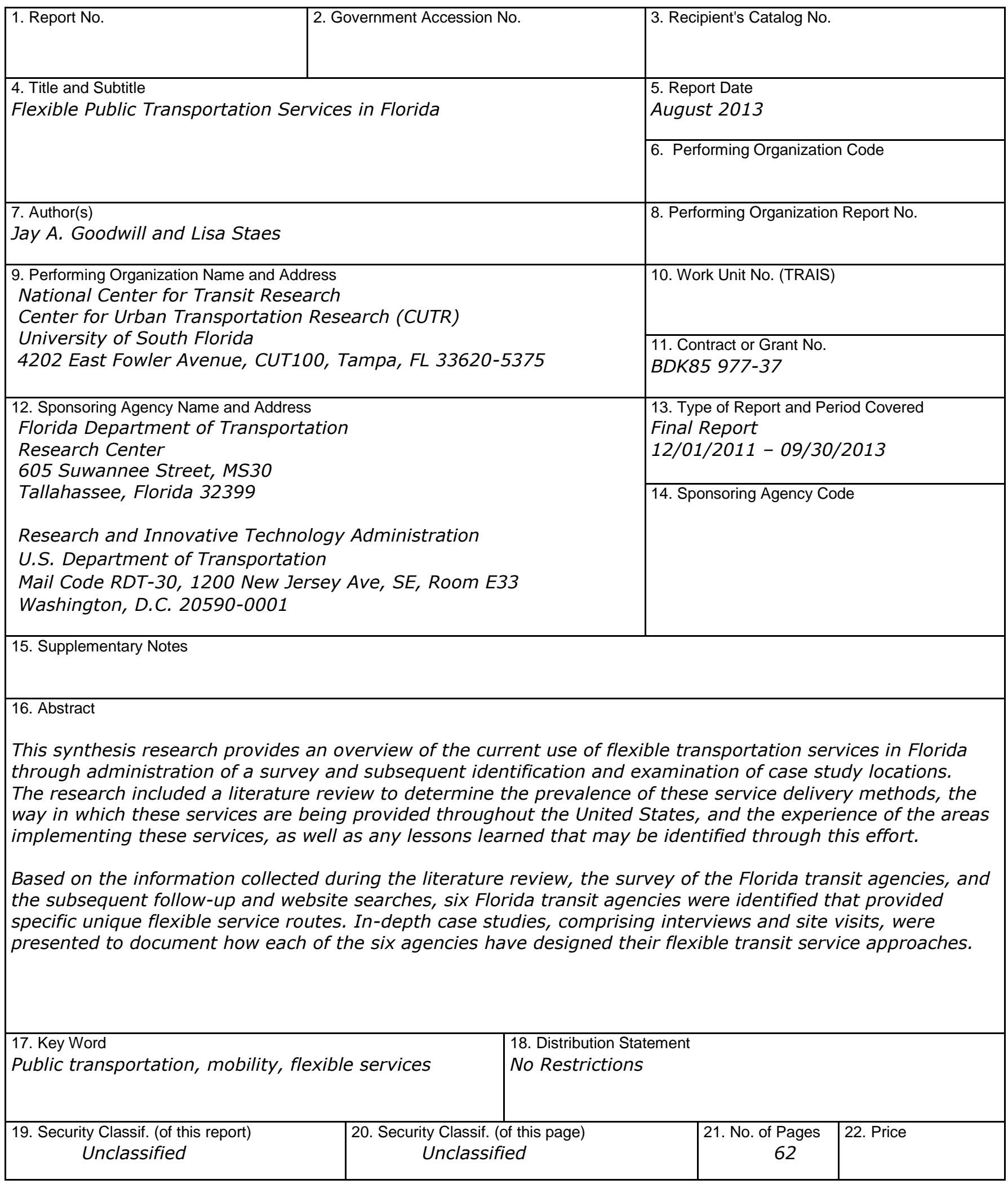




\section{Executive Summary}

Due to the increasing demand to provide public transportation services as efficiently as possible and meet the mobility need of diverse markets and environments, a number of transit agencies have developed and deployed flexible transportation services. These nontraditional service delivery models have proven to be a more cost-effective method to meet the need for transit services in areas of relatively low or irregular demand, including suburban, small urban, and rural markets. They also show great promise in efficiently addressing Americans with Disabilities Act (ADA) complementary paratransit service requirements. The transit industry, through research such as this report and recent TCRP efforts, has provided some structured definitions to a variety of flexible transportation services, including these six basic service models: route deviation, point deviation, demandresponsive connector, request stops, flexible-route segments, and zone routes.

Among the motivations for moving toward greater use of flexible services are reducing expenses, improving existing transit service, serving low density areas, serving special needs populations, and reducing the need for traditional paratransit services.

This synthesis research provides an overview of the current use of flexible transportation services in Florida, obtained through the administration of a survey and subsequent identification and examination of case study locations. The research included a literature review to determine the prevalence of these service delivery methods, the way in which these services are being provided throughout the United States, the experiences of the areas implementing these services, and any lessons learned from those providing the services.

Based on the information collected during the literature review, the survey of the Florida transit agencies, and the subsequent follow-up and website searches, six Florida transit agencies were identified and asked to provide information about their specific flexible service routes. The case studies detailed in this report were developed to provide a summary of each agency's approaches to the delivery of flexible transit services. The six case study agencies included:

- Hillsborough Area Transit Authority (HART), Tampa, Florida

- Jacksonville Transportation Authority (JTA), Jacksonville, Florida

- LYNX, Orlando, Florida

- Lakeland Area Mass Transit District, Citrus Connection, Lakeland, Florida

- Pinellas Suncoast Transit Authority (PSTA), St. Petersburg/Clearwater, Florida

- Volusia County Transit (Votran), Daytona, Florida

Flexible transit routes within Florida were originated within the past decade (i.e., JTA in the mid-2000s, followed by LYNX in 2007) with the addition of other flexible services in 2010 (i.e., Votran in 2010, and HART in 2010 and 2011). The most recent Florida flexible transit services were introduced in December 2012 (i.e., PSTA and Citrus Connection). All of these 
services appear to be well established and well received, with all six transit agencies exploring additional expansion of flexible transit routes.

Flexible transit routes have allowed these Florida transit agencies to replace underperforming fixed routes and expand transit service to non-traditional, low density service areas. The use of smaller buses has improved access to neighborhoods that were inaccessible by larger transit buses. In all cases, the Florida transit agencies have used their flexible routes to provide feeder and distributor service to and from their fixed route networks.

Although each of the Florida flexible transit services is unique, there are some common "rules of thumb" that surfaced upon closer examination of these services:

- Realistic expectations of the application of flexible services are important.

- Expected productivity will probably not exceed 6 to 8 passengers per hour.

- Flexible service zones should be limited to 5 to 7 square miles.

- Route deviations, if employed, should return to the route to its point of departure.

- Timed connections with the fixed route network are critical.

- Special reduced fares can be used as incentives, but adoption of the system base fares is also commonly used.

- Reduced service hours and spans used for the flexible services provide cost savings.

- Smaller buses improve access to passengers and result in lower operating expenses.

- Utilization of technology is important for efficient operations.

- Dedicated dispatch is essential if multiple flexible routes are in service.

The use of flexible transit services in Florida is now well established and continues to evolve. Multiple service options and alternatives have been employed, with each tailored to fit local need and operating policies. Flexible transit services recently introduced appear to be well received by the public, and interest in additional flexible services is strong. 


\section{Table of Contents}

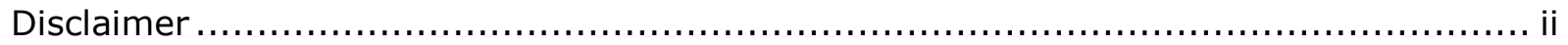

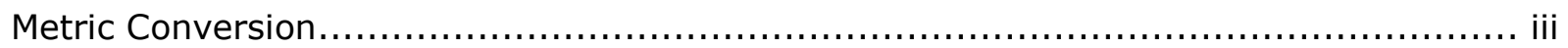

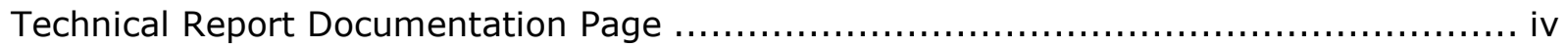

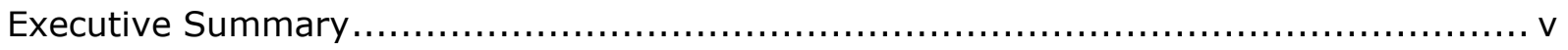

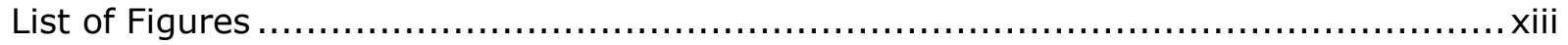

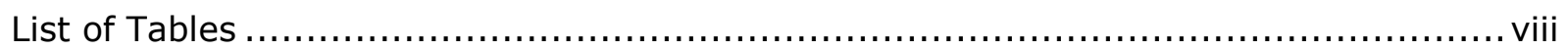

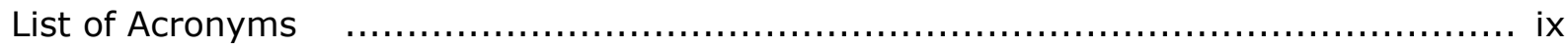

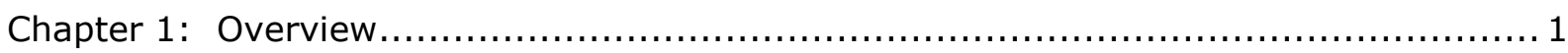

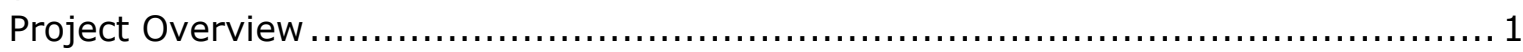

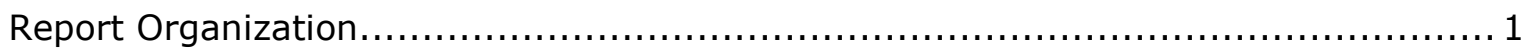

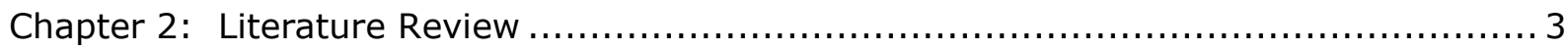

Chapter 3: Current Use of Flexible Public Transportation Services in Florida.............. 11

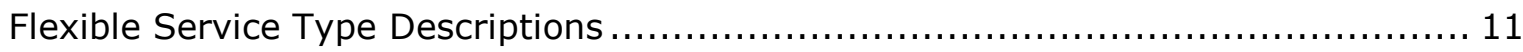

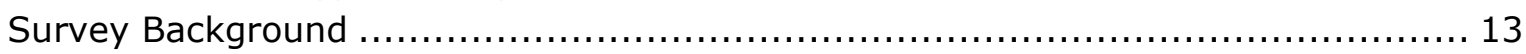

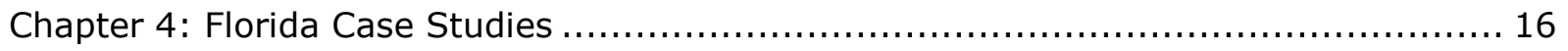

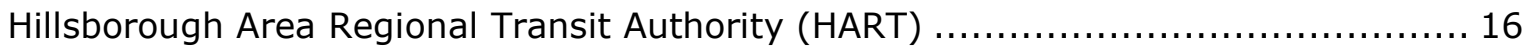

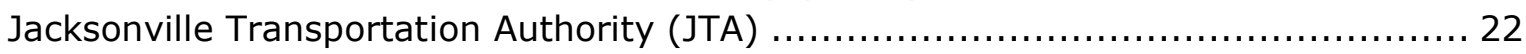

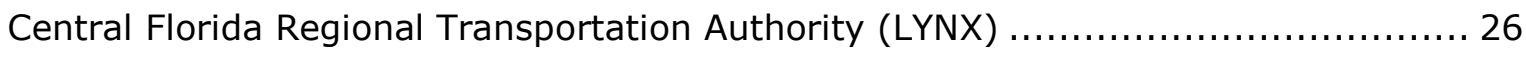

Lakeland Area Mass Transit District (Citrus Connection) ............................... 29

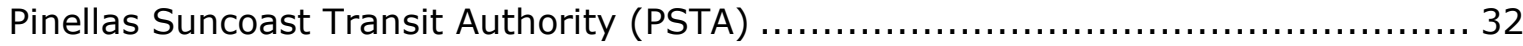

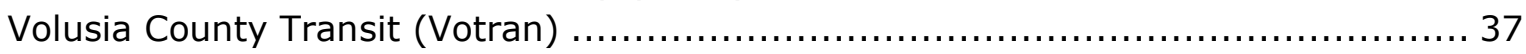

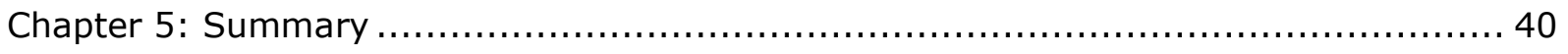

Planning Considerations for Flexible Transit Services................................ 41

Appendix A

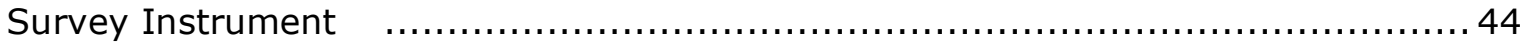

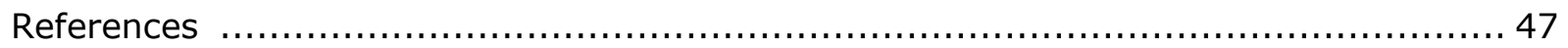




\section{List of Figures}

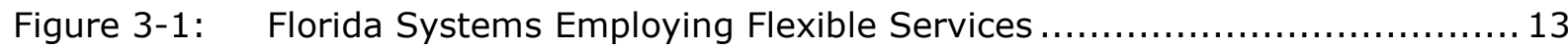

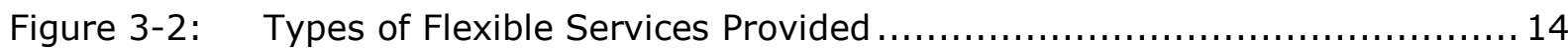

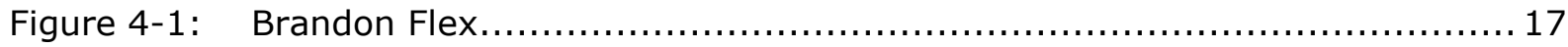

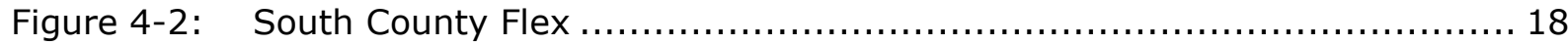

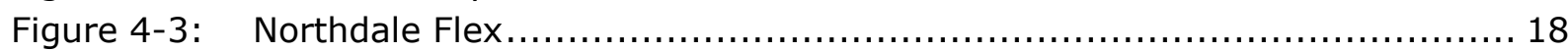

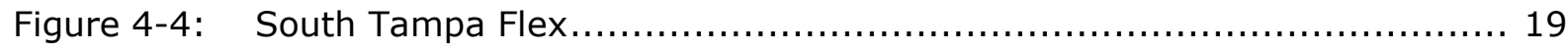

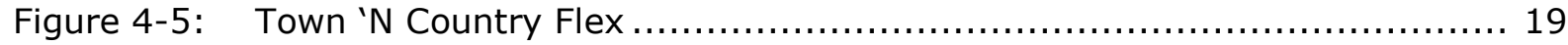

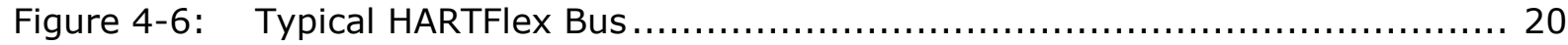

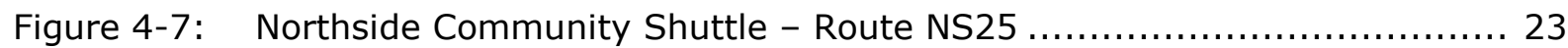

Figure 4-8: Highlands Ride Request Service Zone.................................. 24

Figure 4-9: LYNX Neighborhood Link 612 - Winter Haven........................... 27

Figure 4-10: LYNX Neighborhood Link 621 - East Colonial Drive/Bithlo .................. 27

Figure 4-11: LYNX Neighborhood Link Bus.............................................. 28

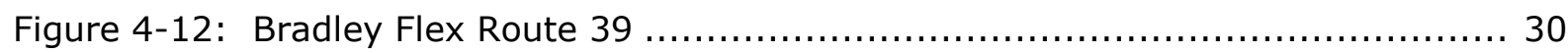

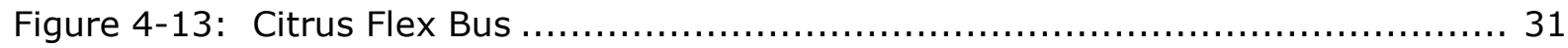

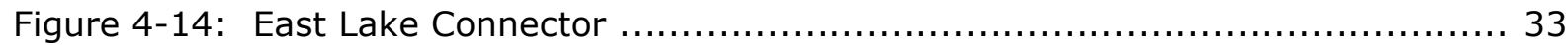

Figure 4-15: Countryside/Oldsmar/Tampa Connector............................... 33

Figure 4-16: Dunedin/Palm Harbor Connector ....................................... 34

Figure 4-17: Combined North County Connector Routes ............................ 34

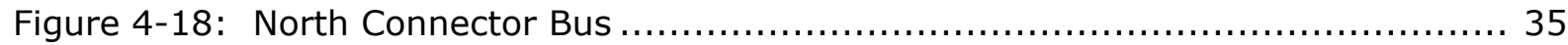

Figure 4-19: Route \#42 Flex Beachside and Route \#43 Flex Mainland .................. 38

\section{List of Tables}

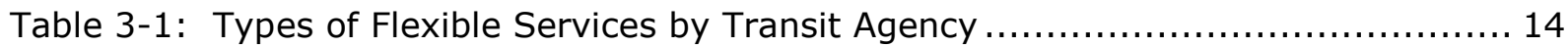

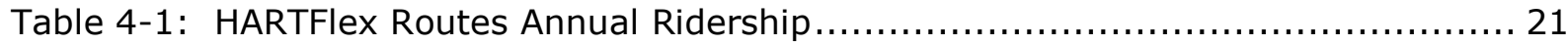

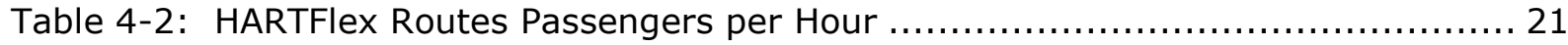

Table 4-3: LYNX Neighborhood Flex Routes Annual Ridership ........................... 29

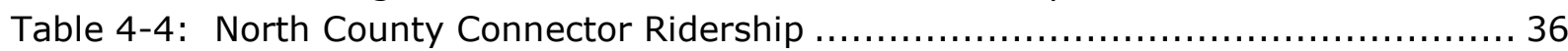

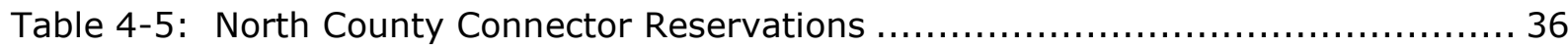

Table 4-6: Votran Flex Services and Fixed Route Cost Comparisons ...................... 39 


\section{List of Acronyms}

ADA - Americans with Disabilities Act

AVL - Advance Vehicle Location

CUTR - Center for Urban Transportation Research

DRT - Demand Response Transit

FTA - Federal Transit Administration

GPS - Global Positioning Systems

HART - Hillsborough Area Transit Authority

JTA - Jacksonville Transportation Authority

LYNX - Central Florida Regional Transportation Authority D.B.A. LYNX

MDT - Mobile Data Terminals

NTB - National Transit Database

PSTA - Pinellas Suncoast Transit Authority

RTD - Denver Regional Transportation District

SAFETEA-LU - Safe, Accountable, Flexible, Efficient Transportation Equity Act: A Legacy for Users

TCRP - Transit Cooperative Research Project

TRB - Transportation Research Board

TRIS - Transportation Research Information Services

Votran -Volusia County Transit 


\section{Chapter 1 \\ Overview}

\section{Project Overview}

Due to the increasing demand to provide public transportation services and meet the mobility need of diverse markets and environments not efficiently served by traditional fixed routes, the transit industry has begun to deploy flexible transportation services. These nontraditional service delivery models have proven to be a more cost-effective method of meeting these demand challenges. They also show great promise in addressing Americans with Disabilities Act (ADA) complementary paratransit service requirements, as well as providing services to areas with low or irregular demand, including suburban, small urban, and rural markets. Flexible transportation services include, but are not limited to, route and point deviations, demand-response connectors to standard fixed route services, by request or "flag" stops, and flexible segments or zone routes.

The Florida Department of Transportation has interest in exploring the current application and future potential for the implementation of flexible transportation services to meet the mobility needs of Florida residents who reside in non-traditional transit areas and visitors to those areas.

This synthesis research provides an overview of the current use of flexible transportation services in Florida through the administration of a survey and subsequent identification and examination of case study locations. The research included a literature review to determine the prevalence of these service delivery methods, the way in which these services are being provided throughout the United States, and the experience of the areas implementing these services.

\section{Report Organization}

\section{Chapter Two - Literature Review}

This chapter presents the findings of a literature review undertaken to determine the current use of flexible transportation services provided throughout the United States. This effort provided an overview of the experience of the areas implementing these services, as well as any lessons learned.

The literature review findings and ongoing research on flexible transportation services were used to direct both the development of the survey that was disseminated to Florida's public transportation providers and the development of the questionnaire used during the case study of six applications of flexible services by Florida transit agencies. 


\section{Chapter Three - Current Use of Flexible Public Transportation Services in Florida}

This chapter offers a framework and descriptions for the types of flexible service alternatives and then focuses on determining the current use of these service types among Florida's public transit agencies.

\section{Chapter Four - Florida Case Studies}

Chapter Four provides a detailed description of six Florida transit agencies that are providing specific unique flexible service routes. In-depth case studies, comprised of interviews and site visits, were undertaken to document how each of the six agencies have designed their flexible transit service approaches.

The case studies were developed to provide a summary of their approaches to the delivery of flexible transit services.

\section{Chapter Five - Summary}

The final chapter delivers a brief recap of this synthesis approach examining flexible transportation services common throughout the United States with specific focus on exploring the current application and implementation of flexible transportation services to meet the mobility needs of Florida residents who reside in non-traditional transit areas. 


\section{Chapter 2 Literature Review}

Due to the increasing demand to provide public transportation services and meet the mobility need of diverse markets and environments not efficiently served by traditional fixed routes, the transit industry has designed flexible transportation service delivery methods. These unconventional service delivery models have proven to be a more cost effective method to meeting these demand challenges. They also show great promise in addressing Americans with Disabilities Act (ADA) complementary paratransit service requirements, as well as providing services to areas with low or irregular demand, including suburban, small urban, and rural markets. Flexible transportation services include, but are not limited to, route and point deviations, demand-response connectors to standard fixed route services, by request or "flag" stops, and flexible segments or zone routes.

The Florida Department of Transportation had interest in exploring the current application and future potential for the implementation of flexible transportation services to meet the mobility needs of Florida residents who reside in non-traditional transit areas and visitors to those areas.

This research provides an overview of the current use of flexible transportation services in Florida through administration of a survey and subsequent identification and examination of case study locations. The research included a literature review to determine the prevalence of these service delivery methods, the way in which these services are being provided throughout the United States; and, the experience of the areas implementing these services, as well as any lessons learned that may be identified through this effort.

\section{Literature Review}

The literature search activity was conducted through the use of the "Transport Research International Documentation" (TRID) system, which combines the records from the Transportation Research Board's (TRB's) Transportation Research Information Services (TRIS) and the Joint Transport Research Centre's International Transport Research Documentation (ITRD) databases. A Google search was also conducted. Additional sources include the bibliographies and references cited in research documents reviewed through this effort. Research and report documents are organized in reverse chronological order (most recently published will be listed first).

The documents summarized in this section include:

- Business Strategies and Technology Access By Transit in Lower Density Environments (Research in Transportation Business \& Management), published in 2011

- Examining Challenges Opportunities and Best Practices for Addressing Rural Mobility and Economic Development under SAFETEA-LU's Coordinated Planning and Human Services Framework (University Transportation Center for Mobility) 2010 
- A Guide for Planning and Operating Flexible Public Transportation Services, TCRP Report 140, released by the TRB in 2010

- Integration of Paratransit and Fixed-Route Transit Service, TCRP Syntheses 76, released by the TRB in 2008

- Transportation Services for People with Disabilities in Rural and Small Urban Communities- Summary Report, (Easter Seals Project Action, 2006)

- Operational Experiences with Flexible Transit Services, TCRP Synthesis 53, released by TRB in 2004.

In Business Strategies and Technology Access By Transit in Lower Density Environments $^{1}$ (R. Teal and A. Becker), the researchers examined the approaches used by the Denver Regional Transportation District (RTD) to provide flexible transportation options to the agency's suburban service areas in a cost-effective manner. Denver has established a menu of flexible service delivery options or a "family of services"; a system that is centered on "a technology platform that enables these services to be delivered with appropriate levels of automation and functionality, ${ }^{2}$ while at the same time supporting welldefined business principles. The service configurations currently employed by RTD include the following:

- Many-to-many on-demand - community based (zoned, neighborhood)

- Feeder to transit network through (timed) transfer

- Point deviation - demand response transit (DRT) with regularly or dynamically scheduled checkpoints

- Route deviation - combination of fixed route with scheduled and/or on-demand checkpoints

- Hybrid services - combinations or variations of the configurations listed above

In the RTD example, these flexible transportation services are targeted to specific market segments, within defined service areas, and are competitively contracted to private service providers.

The technology platform is the central key to the success of RTD's structured DRT. RTD worked closely with a software development firm to design and deliver a technology product that would ensure the success of cost reduction strategies, such as the "Call-n-Ride" system. The design includes a "driver-centric" framework, which includes a mobile device for each driver with software applications for order taking, scheduling, and trip manifest management. There are no reservation agents, schedulers or dispatchers. It is designed with a low interaction customer service structure that includes Web-based self-service or notification-based mechanisms, including real time automatically generated and transmitted messages regarding service status, including vehicle schedule.

One critical component to this technology application is the capabilities that are provided to RTD to examine the structure of the system through extensive data collection and reporting/analysis. This GIS-based structure captures origin and destination data, ridership at specific scheduled checkpoints, capacity issues, passenger cancellations, no-shows, ontime performance, and travel speeds. The use of this data is used to support service modifications design to improve both individual service area and network productivity. 
When comparing RTD's standard DRT services (the many-to-many on-demand service) to the "structured DRT" or flexible service options, service productivity increases from 3 to 4.5 passenger trips per service hour to 5 to 9 passenger trips per service hour, a 50 percent increase in productivity.

The research conducted confirmed that in situations where demand for public transportation services is low and difficult to support by traditional means because of low density development, "DRT and related flexible services offer promise of being the most costeffective solutions." ${ }^{3}$ The use of technology to support these services, allows service configuration changes to be fluid, recognizing changes in demand patterns and reacting through restructuring to allow for more local circulation options or greater connectivity to the fixed route mainline systems, as examples. This creates a better designed public transportation network that is more responsive to the needs of RTD riders, while at the same time effectively managing costs.

\section{Examining Challenges, Opportunities and Best Practices for Addressing Rural Mobility and Economic Development under SAFETEA-LU's Coordinated Planning and Human Services Framework ${ }^{4}$ (Martin, Giusti, Dumbaugh, and Cherrington) analyzed the process used by the twenty-four planning regions in Texas to develop coordinated transportation plans. The objective of the study was to identify planning processes and outcomes that proved most successful in coordinating transportation services and fostering delivery system innovations across various public transportation programs. The study also identified those processes that were less successful.}

The study included the distribution of a survey instrument that targeted agency representatives who led the planning efforts. Thirty-one questions were included within the survey organized within the following topic areas: planning process, plan outcomes, plan assessment, and respondent's leadership style. Included within the segment on plan outcomes, were questions related to the level of coordination within the planning process, interagency coordination agreement, changes to rural transit services, and changes to outreach strategies as a result of the coordinated planning effort. The study found that more than half of the regions are following coordination strategies in their coordination plans; using a mobility manger or broker for coordination service; centralizing reservations, scheduling, and dispatch; jointly training drivers and conducting vehicle procurements; sharing fuel and insurance cost; and jointly delivering service.

The respondents indicated the coordinated planning effort led to greater coordination among agencies, additional interagency agreements, and positive outcomes related to the expansion of services, particularly in the rural areas. Fifty-two percent of respondents indicated that the coordinated planning effort resulted in changes to the way in which services are now provided, including the use of flexible routes.

The study recognizes that coordinated planning efforts can be very successful, but did caution that significant challenges to coordination remains, including inadequate funding, regulatory constraints, and the ability to build trust and sustain long term coordination efforts. 


\section{A Guide for Planning and Operating Flexible Public Transportations Services, TCRP} Report $140^{5}$ (John Potts, Maxine Marshall, Emmett Crockett and Joel Washington) includes a comprehensive review of the various flexible transportation service strategies that have been implemented across the United States and Canada. The guide discusses a number of considerations that must be made prior to implementing flexible services. These include estimating the fiscal impacts, determining the operational and institutional issues, and identifying the complexities within the organization and service area that must be overcome and addressed in order to effectively implement and sustain a program. The guide provides best practices in implementing flexible service identified through the research and includes a number of actions agencies can take in order to implement flexible service.

Strategies are organized to reflect those most appropriate for rural transit providers and those most appropriate for transit systems considered small, medium, and large urban. The guide includes a framework or decision matrix to support an agency's decision to implement a flexible service structure and, if so, how to provide these services.

The project team collected information from a variety of transit systems in rural and urban operating environments. The information collected from these agencies included:

1. The characteristics of the transit provider's flexible service

2. The transit provider's reasons for considering flexible service

3. The way in which the flexible service was implemented

4. The benefits of implementing the flexible service

5. The political environment

6. Operational considerations ${ }^{6}$

Some of the reasons reported by agencies for implementing flexible public transportation and the associated benefits included:

- Improving demand responsive systems

- Serving special needs population

- Replacing fixed route service

- Eliminating or reducing need for paratransit service

- Connections to other public transportation service

- Providing public transportation to low density areas

In the discussion of best practices and decision tools, as an example, the authors suggest that in small urban areas, agencies with current fixed route service should look at their systems productivity rate to determine if a route has a productivity rate of "fewer than 15 passengers for per hour." 7 In this scenario, a proposed flexible transportation system projected to achieve a productivity rate of up 15 passengers per hour could be supported to replace the fixed route in the area. The report further suggests that agencies review trip purposes and population densities, which would influence route schedules and the number and type of deviated service trips offered. 
The report discusses the decision making steps that should be taken to determine the type of vehicle most appropriate to provide these services. It suggests that the selection of vehicles for flexible service should consider the following factors: passenger loads, ridership characteristics, funding, travel lane width, route distances, and agency preference. The report also addresses technology applications, identifying and discussing the most common type of technologies used by flexible transportation service and the benefits of those systems including voice radio, cell phones, scheduling and dispatching systems, Advance Vehicle Location (AVL), and Geographic Positioning Systems (GPS).

The report includes a section on best practices, highlighting six agencies operating flexible transportation service including: Mason County Transportation Authority (Washington), Pierce Transit, City of St. Joseph (Missouri), Potomac and Rappahannock Transportation Commission (PRTC) (Virginia), Regional Transit District (RTD) (Colorado), and Jacksonville Transportation Authority (JTA)(Florida)[. The best practices discussion includes flexible service area characteristics, types of flexible service operated, productivity standards, reasons for implementing service, and marketing strategies.

Integration of Paratransit and Fixed-Route Transit Service, TCRP Syntheses $\mathbf{7 6}^{\mathbf{8}}$ (Richard Weiner) this report examines the level of success experienced by several of the nation's public transit systems with the integration of their fixed route and paratransit services in expanding the services provided and improving the efficiencies of their systems, including efficiencies in the delivery of ADA services.

The focus areas of this study are those services that were either designed specifically to improve the mobility of people with disabilities or those that have benefitted these individuals, and those designed to reduce the demand on ADA complementary paratransit services. The integration methods examined included service structures such as paratransit feeder systems, community buses or circulators, connectors, route deviation, and incentive programs designed to move people from paratransit to fixed route services. In this study, feeder service is the primary variable service delivery method discussed.

Feeder service tends to serve the general public, people with disabilities and the elderly. At the time of this study, the use of feeder services was just beginning, generally coming after the establishment and implementation of an ADA eligibility screening process. According to the report, fixed route disability ridership tends to increase when other services are offered together, such as eligibility screening, travel training, free fixed route fare for people with disabilities, or when connector bus service is provided. Additional training for eligibility screeners, drivers and schedulers has also contributed to the success of the feeder service.

Findings in the study include, but are not limited to the following:

- Systems that have implemented fixed route deviation services have found it to be a valuable means of either avoiding the cost of ADA complementary paratransit, or providing mobility options to underserved areas. 
- Services that connect to the fixed route, whether through a community bus, route deviation, or paratransit feeder services, can be effectively implemented in areas of variable land use densities.

- Geographically elongated and physically constrained service areas are particularly well-suited to feeder service.

- The majority of systems that had implemented these flexible service options indicated a reduction of system operating costs and overall better fiscal efficiencies.

- Educating riders and paratransit staff (i.e., eligibility screeners, schedulers, and drivers) was identified as a critical element. ${ }^{9}$

Factors identified as contributors to public transit agencies electing to not implement these service variations included the concern that the service may negatively impact riders, impeding their ability to maintain their mobility; a perception by public transit agencies that these flexible service scenarios would be difficult to establish and maintain in their communities; and the lack of documented evidence that flexible services reduce operating costs and provide overall system savings.

In those areas that had implemented flexible services, factors that contributed to the discontinuation or reduction of these services included low ridership, lack of interest from riders, or the service was replaced with a traditional fixed route.

The best practices or "exemplary approaches" identified in the study include offering free fixed route passes to ADA paratransit riders, promoting the use of neighborhood circulators through an ADA call-in center, and posting transit staff members at transit center to assist people with disabilities in successfully completing system transfers between modes.

Transportation Services for People with Disabilities in Rural and Small Urban Communities, ${ }^{10}$ (Easter Seals Project Action by TranSystems, Corp, RLS \& Associates, and Nelson $\backslash$ Nygaard Consulting Associates, Inc.) documents the challenges and development strategies that have been employed to provide transportation services to people with disabilities. This multi-dimensional approach evaluates and provides solutions to some of the most commonly listed barriers and challenges to these services.

The report discusses:

- funding limitations

- level of resource/funding coordination that exists

- barriers to the coordination of services

- service restrictions in the form of limited service hours or trip purposes

- "client only" trips

- high costs to provide services

- vehicle accessibility

- limited driver training

The report provides a description of service delivery methods that have met with success including transportation voucher programs, flexible services, the use of taxi cabs and 
volunteers, private auto support programs, and the expanded use of existing transportation services. It further describes the way in which technology has improved transportation service reliability and effectiveness.

The report identifies both federal and state grant programs that can be used to purchase vehicles and equipment, and cover a portion of the agency's operating costs, including the costs associated with providing transportation services for the elderly and disabled. The report highlights successful programs that have been implemented that have either created new funding avenues or more efficiently utilized the available funding available to support transportation services for people with disabilities.

The report describes flexible service delivery methods as successful alternatives to traditional fixed route and paratransit services. The authors conclude that flexible services provide affordable and convenient rural transit service to low-density areas and provide increased mobility for people with disabilities. They reference rural transit agencies that have found that flexible services can reduce costs and better meet the needs of seniors and people with disabilities who might not be able to use fixed-route service. Rural agencies have also found success in using flexible route service for connecting outlying communities to regional public transit service. "Deviating off route can increase the coverage provided in the service corridor and can make the service useful to individuals unable to get to stop due to distance or disability." ${ }^{11}$ In small communities flexible service is often a part of other services such as supplementing demand responsive for flex service to meet the community's needs. They describe the added benefit that flexible services are considered to be demand responsive under ADA and therefore the agencies providing these services "do not need to provide complementary ADA service in the area where flexible service is provided."12

The report highlights technology applications that provide the necessary tools that can help flexible service and demand responsive operators with reservations, dispatching, and scheduling, making services more efficient. In addition, the authors report that the use of technology makes it easier to track and bill clients for trips. The study provides examples that include the use of Automated Vehicle Location ( $A V L$ ), which can make it easier to assign trips in real time, and Mobile Data Terminals (MDTs), which can improve data collection and the reporting of passenger and vehicle information for each trip.

Operational Experiences with Flexible Transit Services, TCRP Report $53^{13}$ (David Koffman) documented the experience of transit agencies that have implemented flexible transit services, including request stops (flag stops), flexible route segments, route deviation, point deviation, zone routes, and demand responsive connector services. The examination includes information obtained through a literature review, a survey of public transit providers, follow-up interviews with transit agency staff, and information contained on transit agency websites.

The report identified 50 U.S. transit systems that have implemented flexible transit services. Through the survey tool, agencies indicated three application scenarios which for flexible 
services made the most sense, with the scenario most noted listed first, followed by those mentioned less frequently:

1. Flexible services provide service in limited areas that are considered hard to serve for reasons of demographics, street layout, or community preferences.

2. They provide service in low-demand time periods. In cities with ample fixed-route service, flexible operation typically substitutes for fixed-route operation in limited areas. In some cities with more limited fixed-route service, flexible operation replaces the entire fixed-route network at certain times.

3. They provide the entire transit service for a small city, low-density suburban area, or rural area. In these cases, coordination or consolidation with paratransit service is a key feature. ${ }^{14}$

The report included a discussion of how flexible services have been marketed, how performance standards and measurements have been utilized, and the barriers and opportunities they recognized. In addition, it also discussed the operational issues that must be considered and addressed when implementing flexible services, such as scheduling and dispatching, staff selection and training, as well as other considerations.

The report included case studies of the following five systems: DART at the Winnipeg Transit System (Manitoba); OmniLink Flex-Routes at the Potomac and Rappahannock Transportation Commission (Virginia); Ride Solutions in Palatka, Florida; flex routes and reservation stops at the Minnesota Valley Transit Authority; and the route deviation service provided by the Ottumwa Transit Authority (Iowa).

The study included the identification of a number of conclusions that were drawn from the survey, interviews, literature review and assessment, and the case studies. The report suggested that flexible transit services can produce benefits for the areas within which they are implemented.

These benefits include:

- Providing cost-effective transit in service areas that are spread out or low-density developed areas

- Providing more cost-effective transit service option during periods of low-demand

- Providing an acceptable balance between customer access and routing effectiveness

- Reducing or eliminating operating expenses associated with the traditional paratransit services

- Laying the groundwork for future fixed route transit services

- Effectively responding to community preferences and geographic considerations ${ }^{15}$ 


\section{Chapter 3}

\section{Current Use of Flexible Public Transportation Services in Florida}

The next task in the research project was to determine the current use of flexible public transportation services among Florida's public transit agencies.

\section{Flexible Service Type Descriptions}

Using the findings of the literature review and in an effort to be consistent with transit industry service descriptions, specifically as detailed in TCRP Synthesis 53 and TCRP Report 140 that were previously cited, the following descriptions of flexible service types were used in our outreach efforts. The graphics included below are those used in TCRP Synthesis $53 .{ }^{16}$

- Route Deviation-vehicles operating on a regular schedule along a well-defined path, with or without marked bus stops that deviate to serve demand-responsive requests within a zone around the path. The width or extent of the zone may be precisely established or flexible.

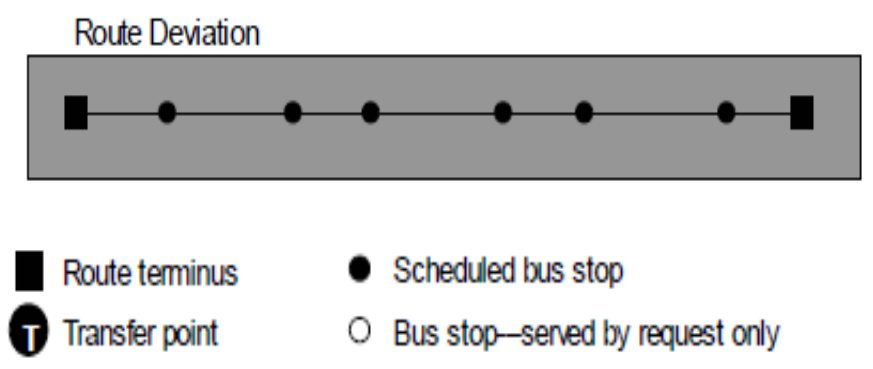

- Point Deviation-vehicles serving demand-responsive requests within a zone and also serving a limited number of stops within the zone without any regular path between the stops.

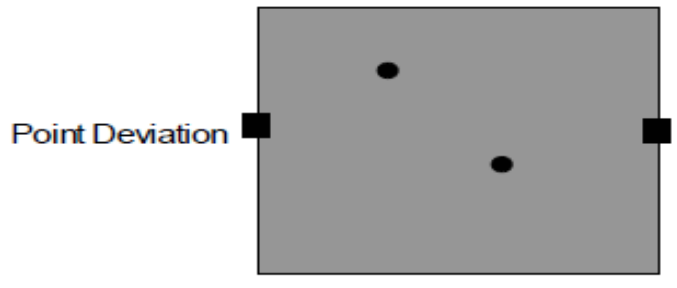

Route terminus

T Transfer point
Scheduled bus stop

O Bus stop-served by request only 
- Demand-Responsive Connector-vehicles operating in demand-responsive mode within a zone, with one or more scheduled transfer points that connect with a fixedroute network. A high percentage of ridership consists of trips to or from the transfer points.
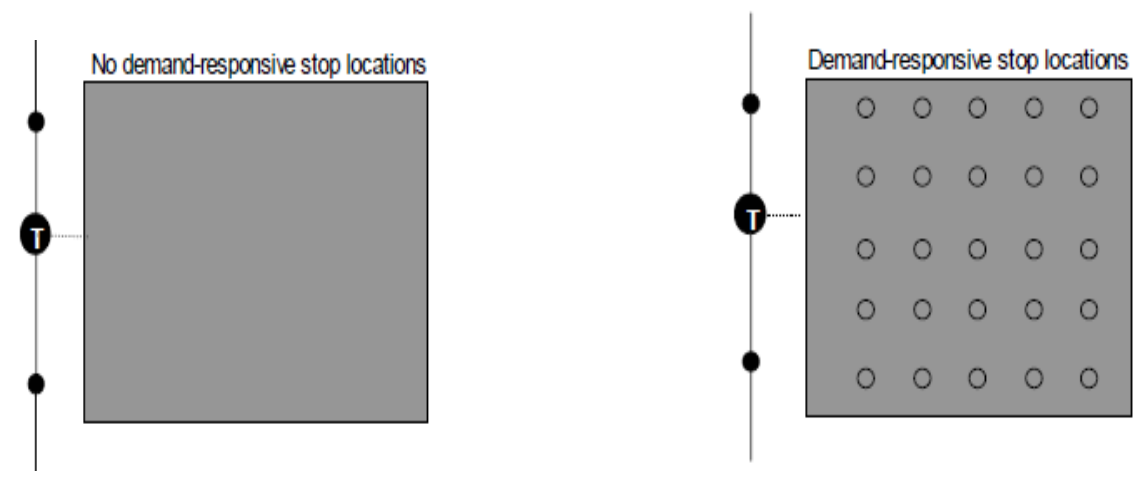
Route terminus
Scheduled bus stop
T Transfer point
O Bus stop--served by request only

- Request Stops-vehicles operating in conventional fixed-route, fixed-schedule mode and also serving a limited number of undefined stops along the route in response to passenger requests.

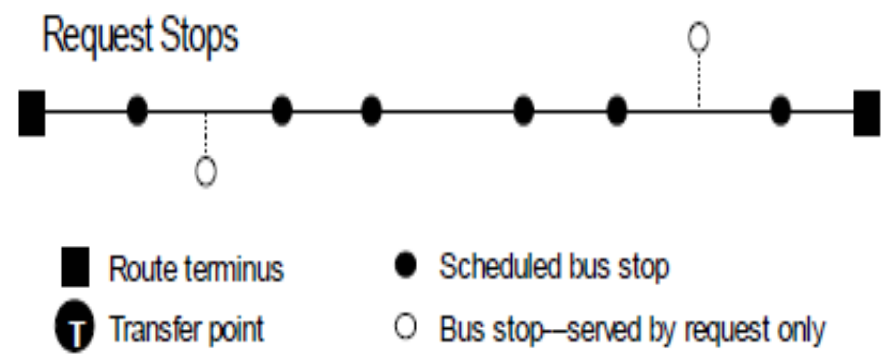

- Flexible-Route Segments-vehicles operating in conventional fixed-route, fixedschedule mode, but switching to demand-responsive operation for a limited portion of the route.

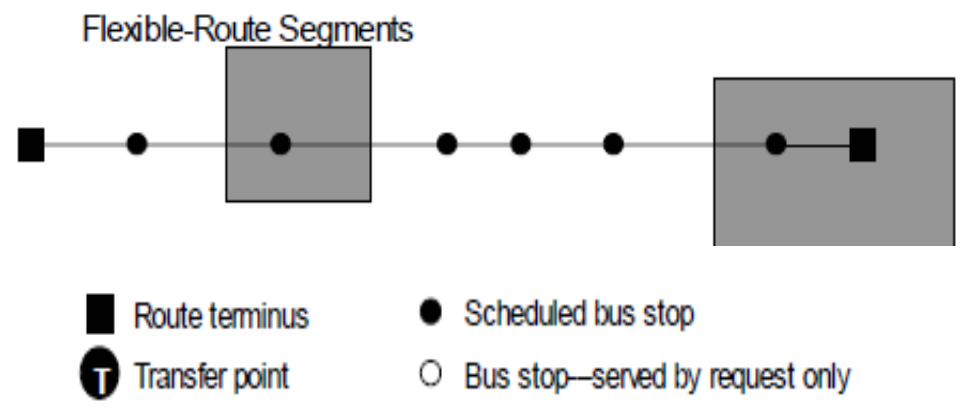


- Zone Route-vehicles operating in demand-responsive mode along a corridor with established departure and arrival times at one or more end points in the zone

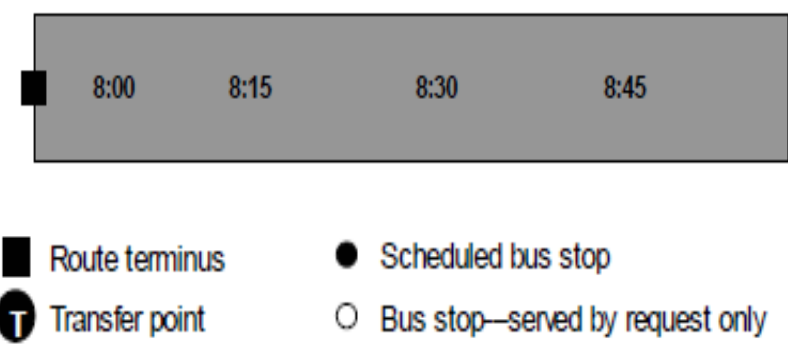

\section{Survey Background}

Due to the variations and complexities of detail of flexible transit service options, the decision was made to first outreach to all of Florida's Federal Transit Administration (FTA) Section 5307 grant recipients with a brief survey to identify this information. Once identified, additional detail and specifics on the flexible services were obtained by website searches and on-site interviews conducted for the case study systems.

The survey instrument, which is included in Appendix B, was designed to provide an overview of the types of flexible service options and then have the responding Florida fixed route transit agencies identify those services that they were currently operating or had operated in the past five years.

The survey was distributed to the Florida Section 5307 grant recipients in mid-July 2013. Subsequent email reminders were sent to encourage responses. The survey was closed in late August with 23 responses, accounting for approximately 70 percent of Florida's fixed route transit agencies.

Subsequent follow up with the non-responding agencies and website searches provided a complete profile of the Florida transit agencies employing some form of flexible transit services. Figures 3-1 and 3-2 graphically summarize the results of these efforts.

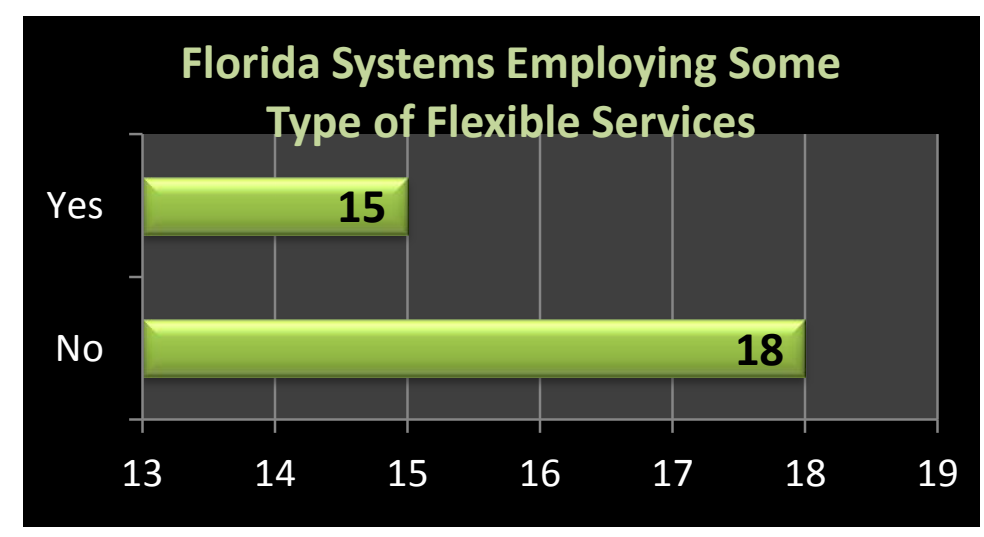

Figure 3-1

Florida Systems Employing Flexible Services 


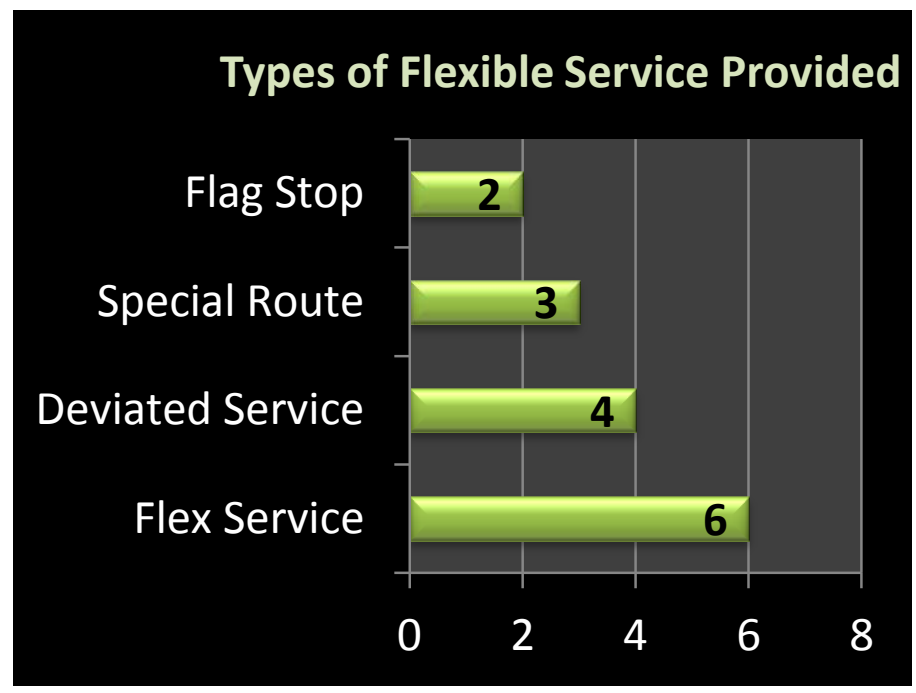

Figure 3-2

Types of Flexible Services Provided

Of the 33 Florida fixed route systems, 45 percent (or 15) systems were providing some form of flexible transit services prior to January 2013. A more detailed summary of the agencies and the types of flexible services they employed is provided in Table 3.1.

Table 3-1

Types of Flexible Service by Transit Agency

\begin{tabular}{|l|l|l|l|}
\hline \multicolumn{1}{|c|}{$\begin{array}{c}\text { Flexible } \\
\text { Service }\end{array}$} & Deviated & $\begin{array}{c}\text { Special } \\
\text { Route }\end{array}$ & Flag Stop \\
\hline JTA & St Johns & Lake & $\begin{array}{l}\text { Space } \\
\text { Coast }\end{array}$ \\
\hline HART & Okaloosa & LeeTran & $\begin{array}{l}\text { Indian } \\
\text { River }\end{array}$ \\
\hline LYNX & Bay & SVTA & \\
\hline Connection & Arcadia & & \\
\hline PSTA & & & \\
\hline Votran & & & \\
\hline
\end{tabular}


The efforts to identify the current use of flexible public transportation services among Florida's public transit agencies revealed 15 systems employing some form of nontraditional transit services. Closer examination determined that of the 15 systems, there were 6 transit agencies are employing flexible transit routes. As will be detailed in the next chapter, the research undertook case studies of these six transit agencies. 


\section{Chapter 4 \\ Florida Case Studies}

Based on the information collected during the literature review, the survey of the Florida transit agencies, and the subsequent follow up and website searches, six Florida transit agencies were identified that are providing specific unique flexible service routes. In-depth website case studies, comprised of interviews and site visits, were undertaken to document how each of the six agencies have designed their flexible transit services.

The case studies detailed in this chapter were developed to provide a summary of each agency's approaches to the delivery of flexible transit services.

The six case study agencies included:

- Hillsborough Area Transit Authority (HART), Tampa, Florida

- Jacksonville Transportation Authority (JTA), Jacksonville, Florida

- LYNX, Orlando, Florida

- Lakeland Area Mass Transit District, Citrus Connection, Lakeland, Florida

- Pinellas Suncoast Transit Authority (PSTA), St. Petersburg/Clearwater, Florida

- Volusia County Transit (Votran), Daytona, Florida

\section{Hillsborough Area Transit Authority}

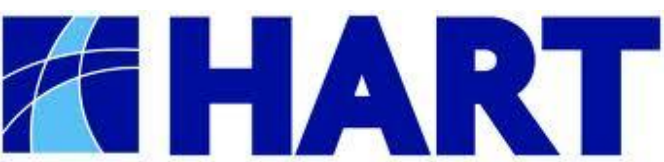

Hillsborough Area Regional Transit Authority

\section{Agency Name}

Hillsborough Area Regional Transit Authority

\section{Agency Description}

The Hillsborough Area Regional Transit Authority (HART) was created in October of 1979 to plan, finance, acquire, construct, operate and maintain mass transit facilities and supply transportation assistance in Hillsborough County.

Today HART operates with a fleet of 177 HART buses, 38 HARTPlus vans and 8 HARTFlex vans. Service is provided with 27 local routes, 12 express routes and 5 Flex routes/zones.

According to the National Transit Database, HART transported 15,117,154 passengers in FY 2011. 


\section{Flex Service Details}

The five HARTFlex routes operate an on-demand with curbside van-based service open to all passengers. This service model would be defined as "route deviation" where the vehicles operate along a well-defined path but are allowed to deviate off route to serve demandresponsive requests within a defined zone. HARTFlex has the advantages of a traditional fixed bus route with the convenience of curbside pickup.

The primary motivation of HART in introducing the HARTFlex service was the opportunity to provide lower cost service to lower density areas, to replace expensive fixed route circulators with a lower cost option, and to provide service to areas not reasonable to serve with full size buses.

HART introduced its first two HARTFlex routes in 2010 in Brandon and South County.

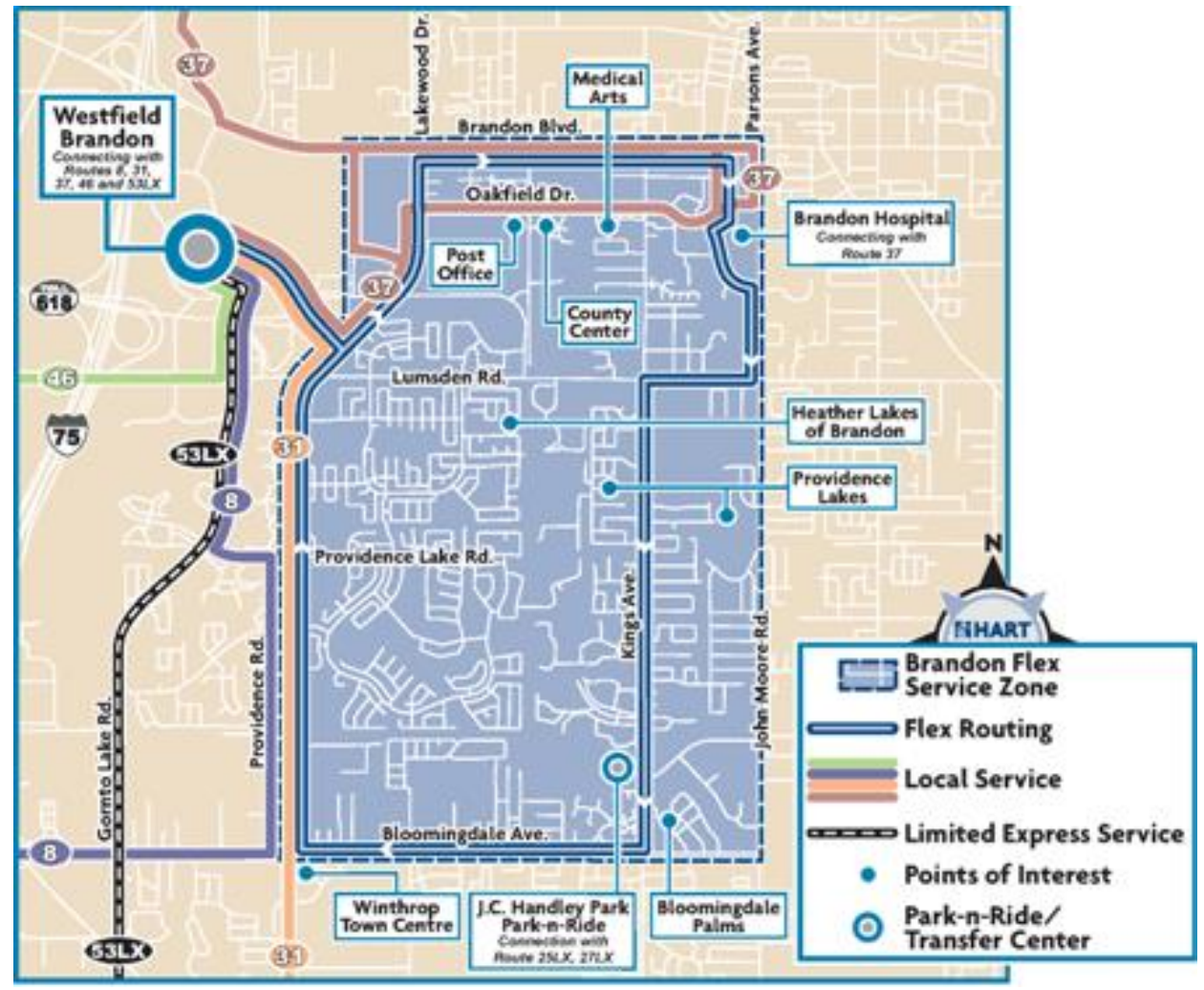

Figure 4-1

Brandon Flex 


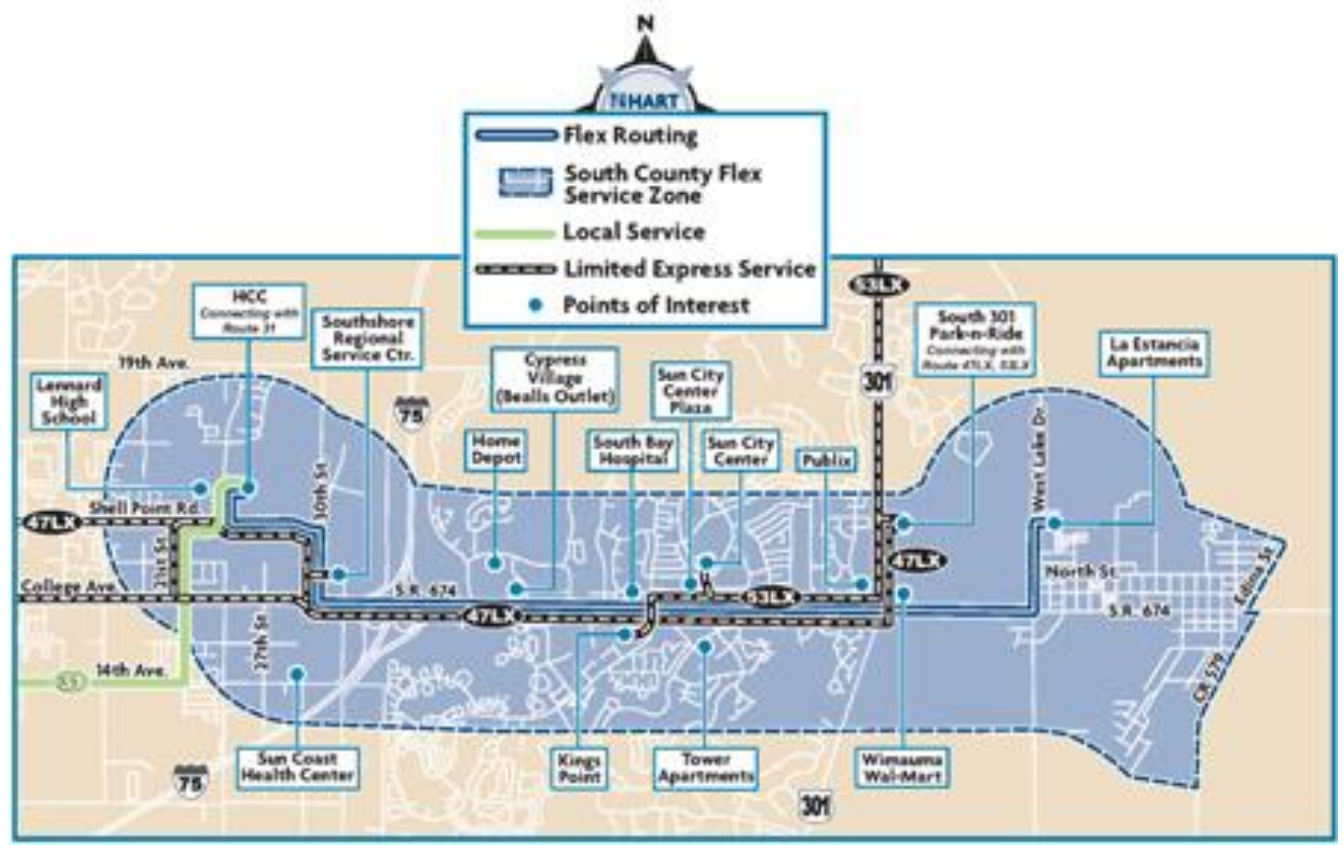

Figure 4-2

South County Flex

Based on their success, three additional HARTFlex routes were added in 2011 in Northdale, South Tampa and Town 'N County.

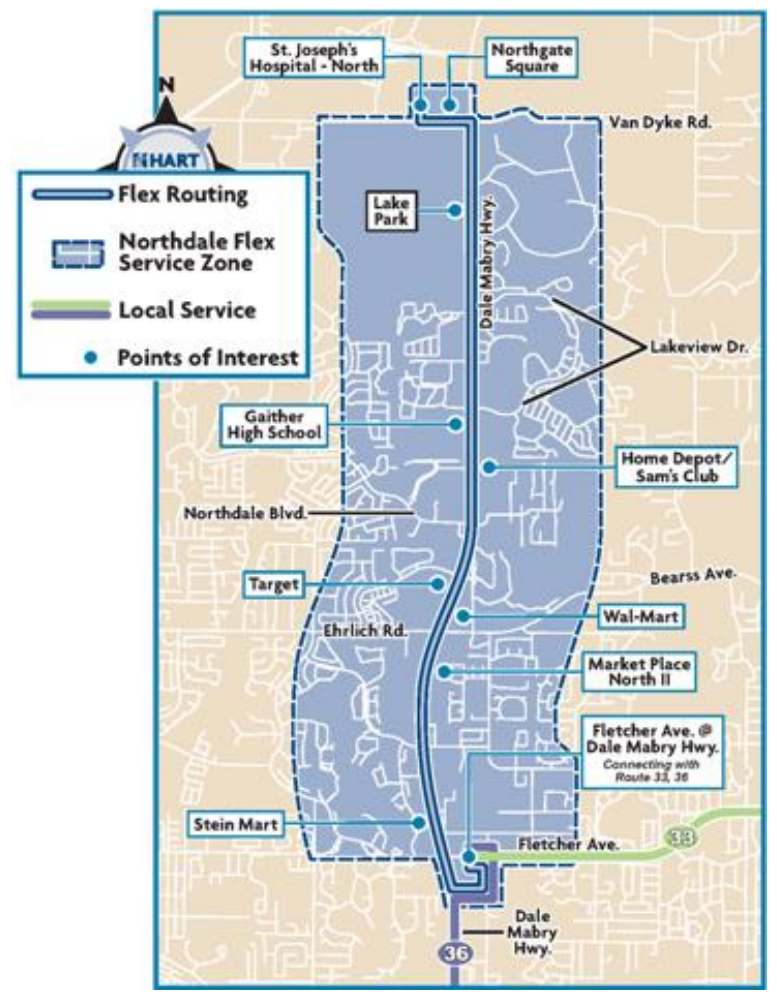

Figure 4-3

Northdale Flex 


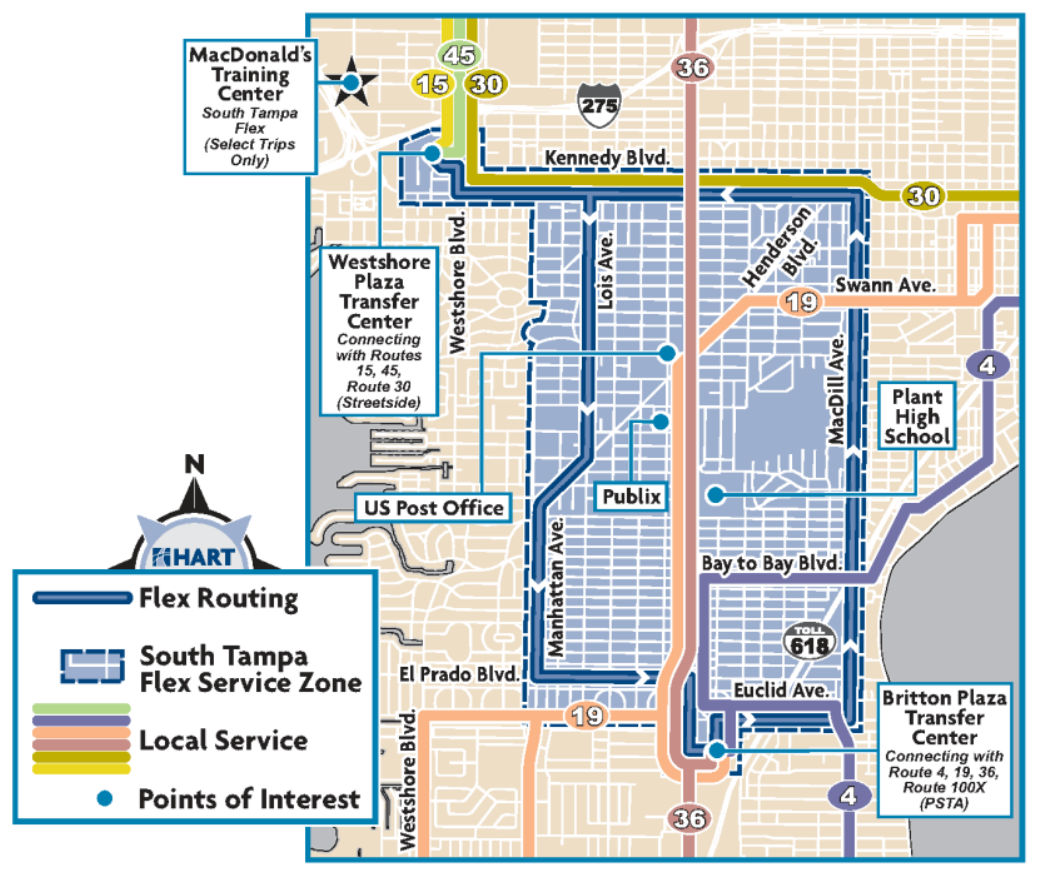

Figure 4-4

South Tampa Flex

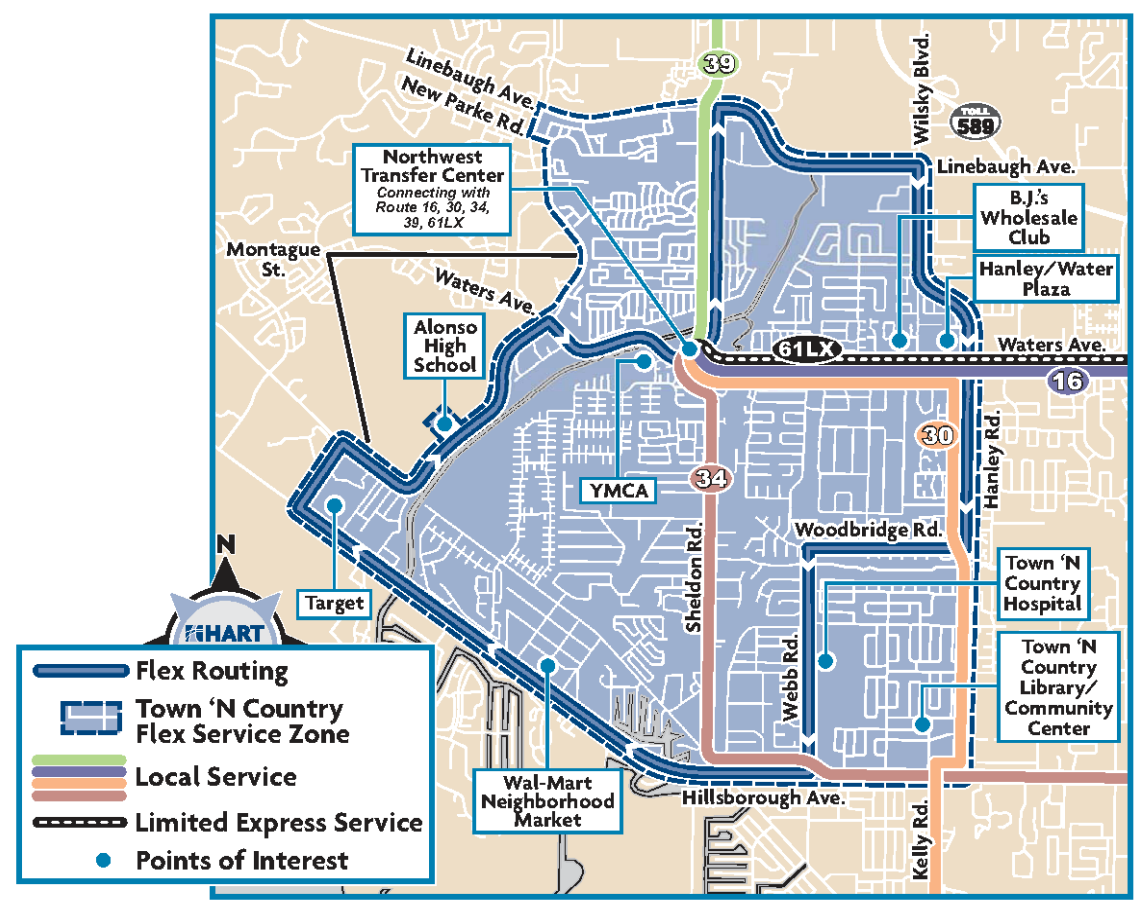

Figure 4-5

Town 'N Country Flex 


\section{Operations}

There are two ways to access the HARTFlex routes. The buses follow a pre-set route, so passengers can board at any bus stop along the route. Flag stops are not permitted. The second option is to arrange for the HARTFlex service to come to the person's origin or destination within the zone. HART's zones are designed to be between 5 to 7 square miles in size.

Requests for the deviated service must be made at least two hours in advance and can be made up to three days prior to the travel. Route deviations are scheduled on a first comefirst served basis and are typically limited to two deviations per round trip. No subscription service is permitted. No standees are allowed on the HARTFlex van.

All HARTFlex fares are $\$ 1$ per person per ride, which is 50 percent of the HART base fare of $\$ 2$. Passengers transferring to the regular HART routes must pay another fare. The regular HART passes are honored for the HARTFlex services.

The HARTFlex routes operate on hourly headways from Monday through Friday from approximately 6:00 a.m. until 8:00 p.m. There is no HARTFlex service on Saturdays, Sundays or on major holidays.

HARTFlex is operated by HART employees, with dedicated schedulers and dispatchers for the service. The HART bus operators are classified as "van drivers" and have a lower pay scale than the fixed route operators.

HART uses 23 foot cutaway vans that seat 12 and can accommodate up to two wheelchairs. The buses are equipped with GFI fareboxes, automatic vehicle locators, mobile data terminal units, and radios.

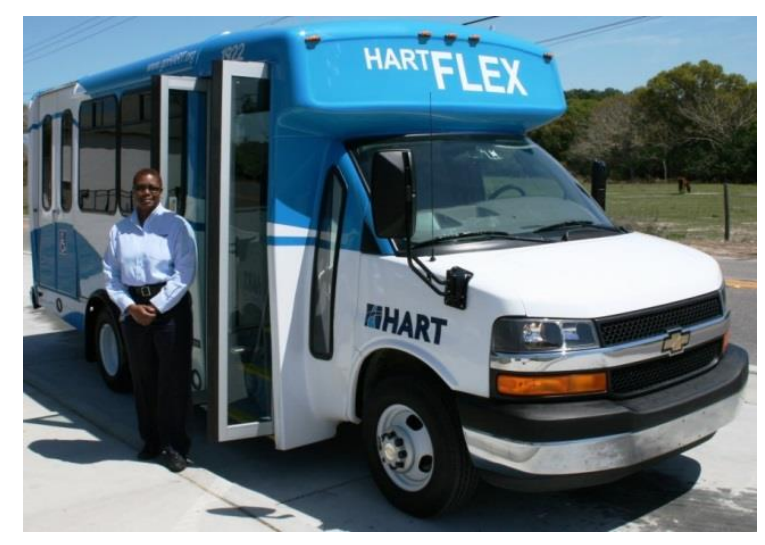

Figure 4-6

Typical HARTFlex Bus 


\section{Outcomes}

Tables 4-1 and 4-2 provide summaries of the annual ridership and productivity of the five HARTFlex routes.

Table 4-1

HARTFlex Routes Annual Ridership

\begin{tabular}{|c|c|}
\hline Route & Annual Passengers \\
\hline Brandon & 5,061 \\
\hline South County & 3,662 \\
\hline Northdale & 25,515 \\
\hline Town N' Country & 5,259 \\
\hline South Tampa & 11,118 \\
\hline System Total & 47,615 \\
\hline
\end{tabular}

Table 4-2

HARTFlex Routes Passengers per Hour

\begin{tabular}{|c|c|}
\hline Route & Passengers Per Hour \\
\hline Brandon & 2.57 \\
\hline South County & 1.69 \\
\hline Northdale & 8.93 \\
\hline Town N' Country & 2.28 \\
\hline South Tampa & 6.15 \\
\hline System Total & 4.42 \\
\hline
\end{tabular}

FY 2012 performance measures for the HARTFlex service were:

- Cost per Passenger

- Cost Per Mile

- Cost per Hour
$\$ 12.32$

$\$ 4.08$

$\$ 52.00$ 


\section{Jacksonville Transportation Authority}

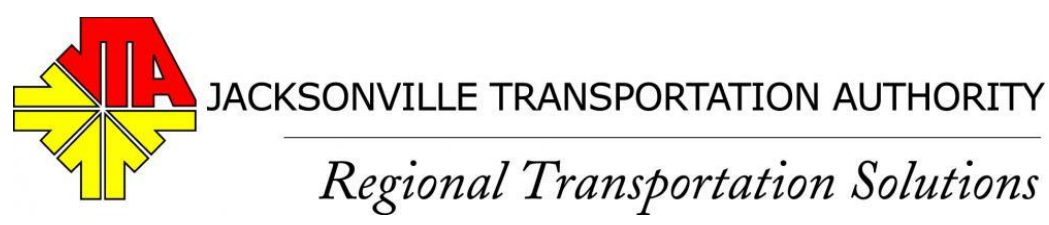

\section{Agency Name}

Jacksonville Transportation Authority (JTA)

\section{Agency Description}

In 1971, the Jacksonville Expressway Authority merged with several private bus companies to form the Jacksonville Transportation Authority. The Jacksonville Transportation Authority provides high quality regional transit services and roadway infrastructure connecting Northeast Florida.

JTA has 56 bus routes with vehicles traveling 8.5 million revenue miles each year with approximately 320 bus operators and 110 maintenance employees supporting an active fleet of 180 vehicles.

According to the National Transit Database, JTA transported $12,639,156$ passengers in FY 2011.

\section{Flex Service Details}

JTA has a long history of providing flexible transit services and has the most extensive flexible service route inventory among all of the Florida transit agencies. JTA currently has 12 flexible service routes (i.e., Neighborhood Services) that are grouped into two types of services: Community Shuttles (10) and Ride Request (2).

\section{Community Shuttles}

The ten JTA Community Shuttles would be classified as "route deviation routes" where the buses operate on a fixed schedule with marked bus stops with the option for the bus to deviate off the route to serve demand-response requests within that route's service zone. The routes provide connections with fixed route JTA service, as well as community activity centers within the zone. The JTA Community Shuttles allow passengers to request "Premium Curbside Service" by calling at least two hours in advance or up to three calendar days in advance of the travel. Route deviation requests are honored on a first come - first served basis and are generally limited to approximately two deviations per trip. The JTA Community Shuttles are open to the public. 
Each JTA Community Shuttle follows a set route within a defined premium service area; an example, the Northside Community Shuttle route, is shown in Figure 4-6.

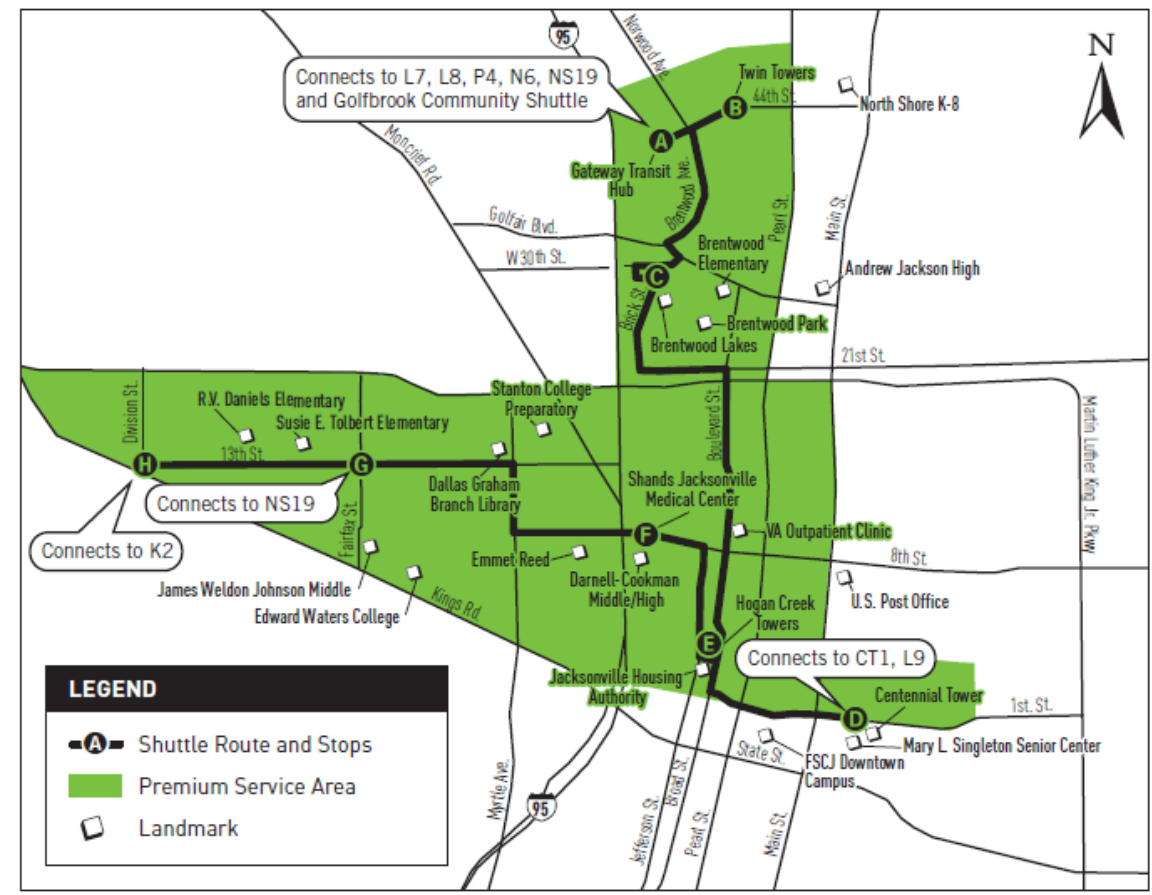

Figure 4-7

Northside Community Shuttle - Route NS25

The ten JTA Community Shuttles include:

- Arlington Community Shuttle

- Beaches Community Shuttle

- Cecil Community Shuttle

- Dinsmore-River City Community Shuttle

- Edgewood Community Shuttle

- Golfbrook Community Shuttle

- Mandarin Community Shuttle

- Northside Community Shuttle

- Ortega-NAS Community Shuttle

- Talleyrand Community Shuttle

Ride Request

The two JTA Ride Request routes would be classified as "demand-responsive connector routes" where the buses operate in a demand-responsive mode within a zone, with one or more scheduled transfer points that connect with the fixed route network. 
The two JTA Ride Request routes, the Highlands and the Oceanway, provide service to the northern sections of the JTA fixed route service area and provide connector service to JTA's fixed route network. The JTA Ride Request routes are open to the public.

Using the Highlands Ride Request Service Zone (Figure 4-7) as an example, each of the JTA Ride Request services are limited to trips within a defined premium service area.

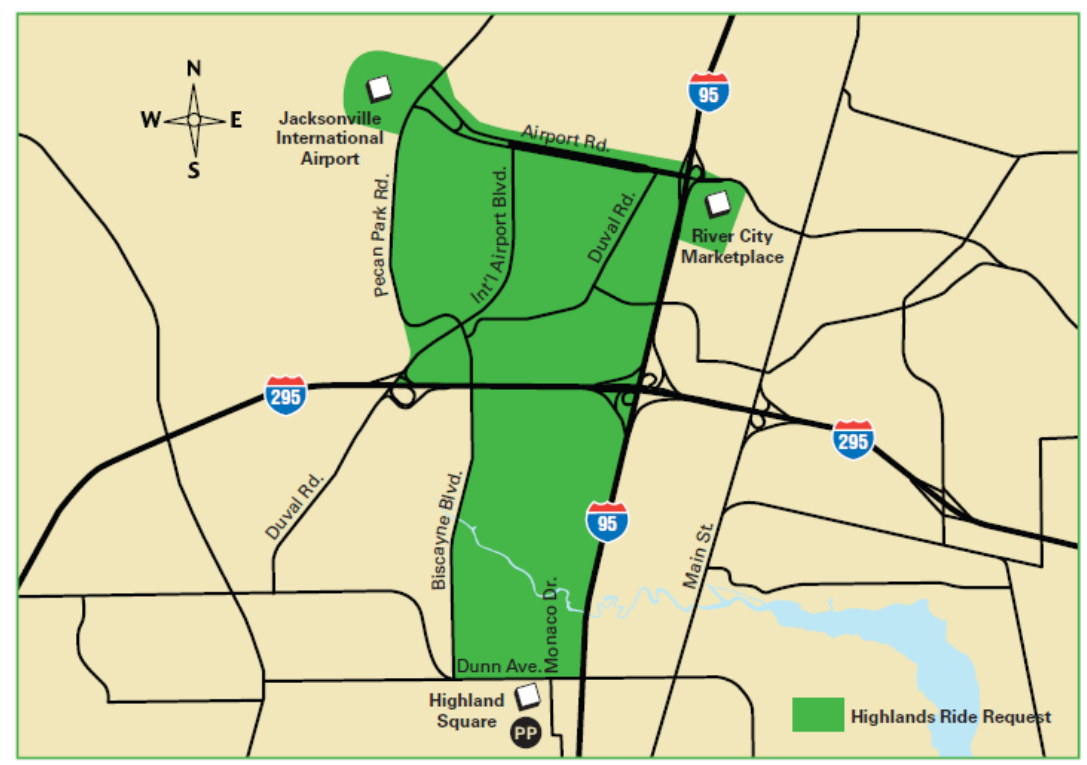

Figure 4-8

Highlands Ride Request Service Zone

\section{Operations}

\section{Community Shuttles}

The JTA Community Shuttles operate seven days per week with reduced service hours on Saturdays and Sundays. Service spans vary by route. These routes are open to the general public.

Passengers can board the JTA Community Shuttles at any stop designated with the Community Shuttle sign. No flag stops are permitted. The service follows a set schedule with specific time points listed on the schedule. Reservations for walkup passengers are not required.

Premium Curbside route deviation service is available upon advance request. Requests must be made at least two hours in advance or up to three days in advance. Requests are honored on a first come - first served basis and are generally limited to two per trip.

Community Shuttle fares are $\$ 1.50$ each trip, which is identical to the JTA fixed route network fare. Individuals with a reduced fare card ride for 50 cents. Seniors, who are 60 years of age and older, ride for free. JTA passes are honored on the Community Shuttles. 
An additional 50 cent fee is charged for the curbside service stops for all fare categories. Transfers to and from the JTA fixed route buses require the payment of an additional fare.

Reservations of the Premium Curbside service are made through the JTA paratransit service center.

JTA Community Shuttles are operated with JTA bus operators.

\section{Ride Request}

The JTA Ride Request routes operate on a set schedule on weekdays. Limited weekend service is provided as regular demand response basis only. These routes are open to the general public.

Ride Request fares are $\$ 2.00$ each trip. Individuals with a reduced fare card ride and seniors are 60 and older ride are assessed a $\$ 1$ each way per person.

Transfers to and from the JTA fixed route buses require the payment of the fixed route fare.

Reservations of the Premium Curbside service are made through the JTA paratransit service center. Requests must be made at least 2 hours in advance or up to three days in advance. Weekly subscriptions are accepted for persons using the service at the same place, on the same day every week.

JTA Request Ride services are provided by contracted paratransit service providers.

\section{Outcomes}

As a group the JTA Neighborhood Services average approximately 51,000 passenger trips monthly. Productivity measures are 7.9 passengers per hour and 6.5 passengers per mile. Average cost per passenger is $\$ 4.63$.

When the Community Shuttle service was instituted in 2008 as part of overall streamlining of the JTA fixed route service, JTA examined service areas and changed their service delivery from four fixed route buses to two fixed route buses supported by a Community Shuttle route. This resulted in an approximate savings of $\$ 350,000$ to $\$ 400,000$ per transition due to less service hours and lower fuel costs due to the reduction of full size buses and the use of smaller cutaway buses for the Community Shuttles. 


\section{Central Florida Regional Transportation Authority}

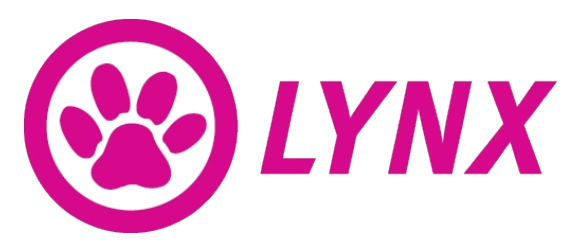

\section{Agency Name}

Central Florida Regional Transportation Authority (CFRTA) doing business as LYNX

\section{Agency Description}

The transit agency was founded in May 1972 as the Orange Seminole Osceola Transportation Authority (OSOTA) and became Tri-County Transit in 1984. The organization began doing business as LYNX in 1992 and became the Central Florida Regional Transportation Authority in March 1994.

LYNX provides service to the Central Florida counties of Orange, Osceola and Seminole, with limited services provided in small portions of Lake, Polk and Volusia counties. LYNX has 71 fixed routes with vehicles traveling 16.5 million revenue miles each year with an active fleet of 270 vehicles. According to the National Transit Database, LYNX transported 28,023,186 passengers in FY 2011.

\section{Flex Service Details}

In addition to its 71 fixed routes, LYNX also operates 10 flex-service routes which are open to the general public, called NeighborhoodLinks. These flexible service routes are designed to make it easier for residents in outlying and less-populated service areas. The original flexible route was put into service in June 2007 as a replacement for a segment of an underperforming fixed route. The ten NeighborhoodLinks routes are:

- NL 601/Poinciana

- NL 603 Southwest Poinciana

- NL 604/Intercession City-Campbell City

- NL 611/Ocoee

- NL 612/Winter Garden

- NL 613/Pine Hills

- NL 621 E. Colonial Drive/Bithlo

- NL 622/Oviedo

- NL 631/Buena Ventura Lakes

- NL 641/Williamsburg

With the exception of the East Colonial Drive/Bithlo route, all NeighborhoodLinks would be classified as "demand-responsive connector routes" where the buses operate in a demand-responsive mode within a zone, with one or more scheduled transfer points that 
connect with a fixed route network. Neighborhood Link 612 is shown in Figure 4-9 as an example of the demand-response connector route.

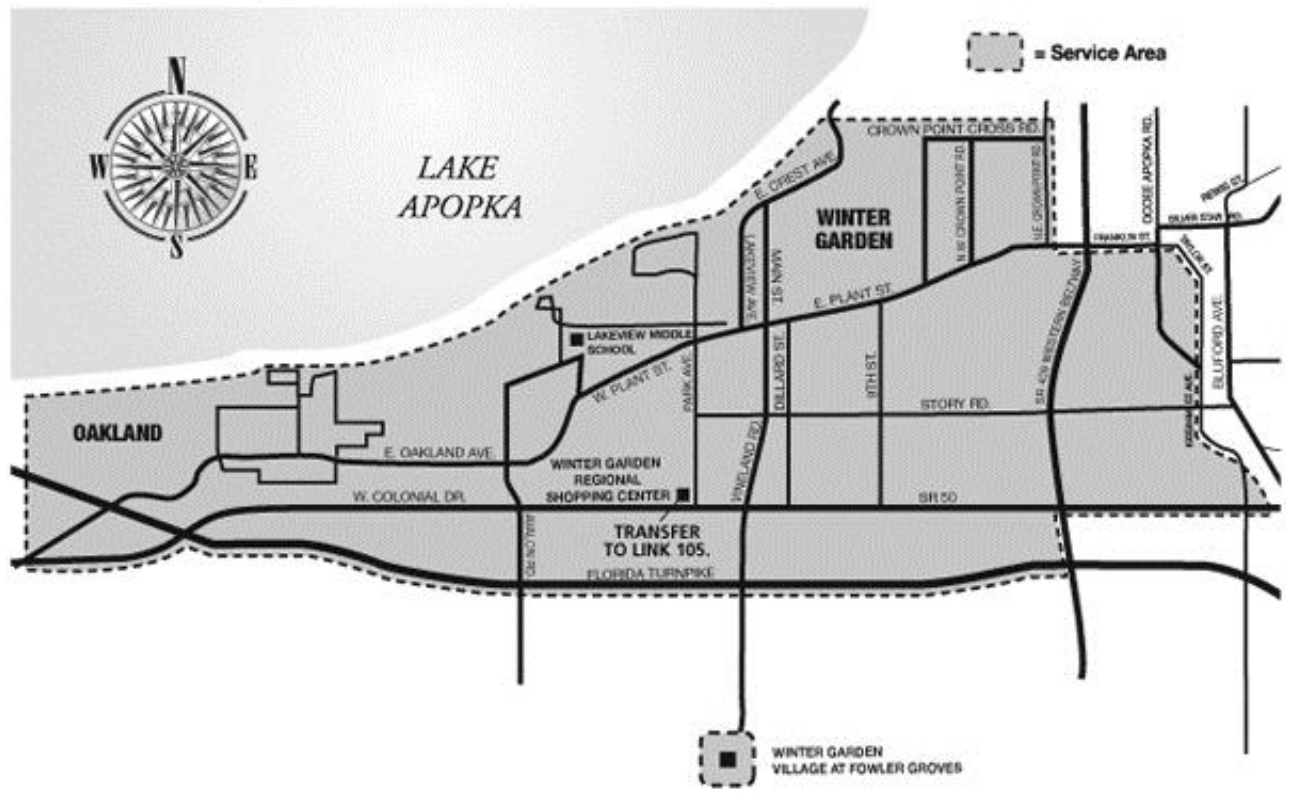

Figure 4-9

LYNX Neighborhood Link 612 - Winter Haven

The East Colonial Drive/Bithlo route would be classified as a "flexible-route segment" where buses operate in a conventional fixed-route, fixed-schedule mode, but switch to demand-responsive operation for a limited portion of the route.

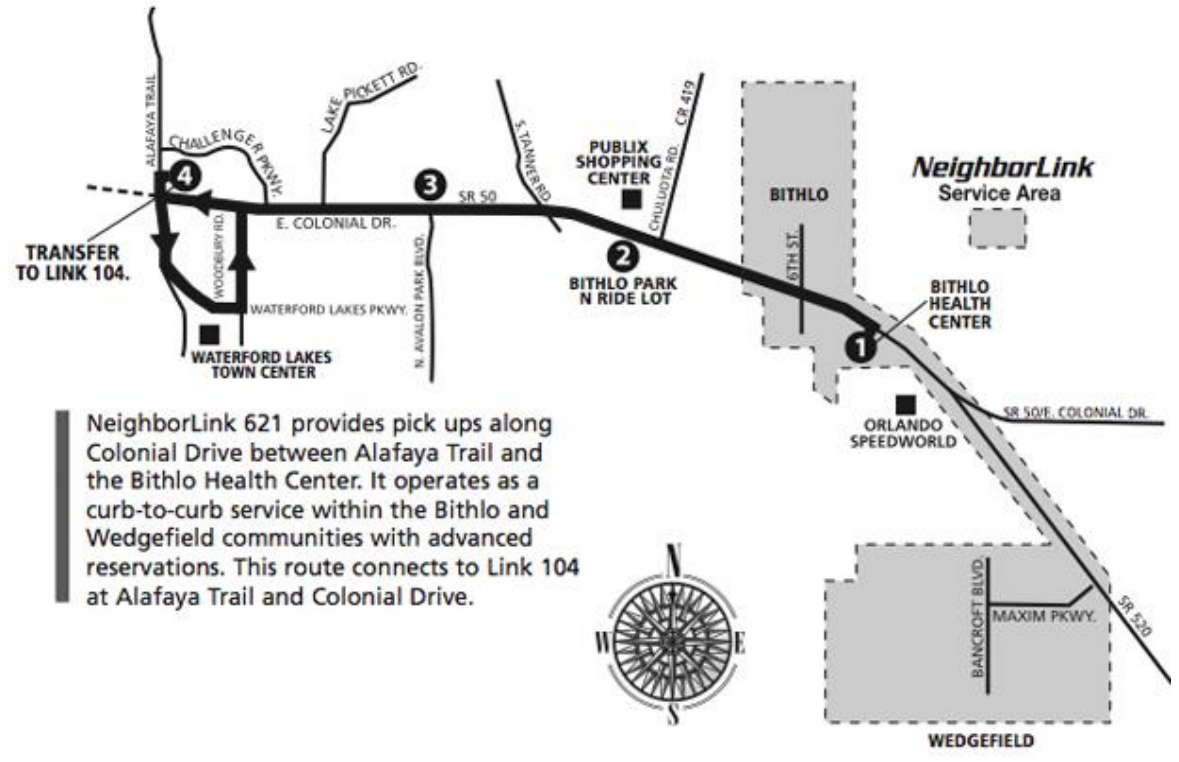

Figure 4-10

LYNX Neighborhood Link 621 - East Colonial Drive/Bithlo 


\section{Operations}

The NeighborLink service provides transportation anywhere within the designated service area or to a nearby LYNX local bus stop.

To travel within their designated service area or to connect to a regular LYNX bus stop, residents must call at least two hours before they want to leave their home and schedule a pickup time. Reservations can be placed up to seven days in advance of the travel. Additionally, subscription trips can be scheduled for regularly schedule trips.

NeighborhoodLinks service operates from 5:30 a.m. to 8 p.m. All service is available Monday through Saturday except in Buena Ventura Lakes and Intercession City/Campbell City where rides are available Monday through Friday.

The fare for the NeighborhoodLink service is the same as the LYNX fixed route service, which is $\$ 2$ per person per ride. Transfers are issued for connections between the NeighborhoodLink and LYNX fixed routes. LYNX offers a variety of fares including the AllDay Pass at $\$ 4.50$; the LYNX 7-Day Pass at $\$ 16$; and the 30 -Day Pass at $\$ 50$. These passes are valid for use on the NeighborhoodLink routes.

The LYNX NeighborhoodLink service is coordinated by a single call taker/dispatcher. The service is operated by contract operators.

These flexible services are provided using 23-foot ARBOC low floor buses. All buses are equipped with mobile data terminals and automatic vehicle locator systems. The scheduling and dispatch is managed with Trapeze Pass software.

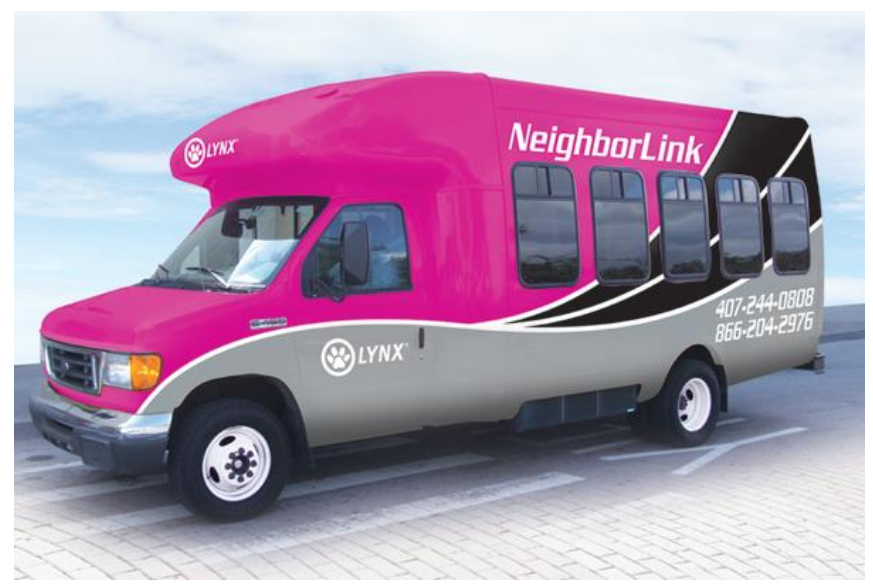

Figure 4-11

LYNX Neighborhood Link Bus 


\section{Outcomes}

The original LYNX flex service was initiated in June 2007. Additional flex routes were added in 2009 and 2010, with the final addition occurring in late October 2012. As detailed in Table 4-3, the NeighborhoodLink composite ridership has increased over the years and has recently been averaging 3.9 to 5.1 passengers per hour.

Table 4-3

LYNX Neighborhood Flex Routes Annual Ridership

\begin{tabular}{|l|l|l|l|}
\hline $\begin{array}{c}\text { Calendar } \\
\text { Year }\end{array}$ & \multicolumn{1}{|c|}{$\begin{array}{c}\text { Annual } \\
\text { Total }\end{array}$} & \multicolumn{1}{|c|}{$\begin{array}{c}\text { Daily } \\
\text { Average }\end{array}$} & $\begin{array}{c}\text { Passengers } \\
\text { Per Hour }\end{array}$ \\
\hline 2007 & 1,294 & 7 & 0.61 \\
\hline 2008 & 8,400 & 27 & 1.98 \\
\hline 2009 & 83,971 & 271 & 5.10 \\
\hline 2010 & 130,287 & 423 & 4.21 \\
\hline 2011 & 147,240 & 478 & 4.21 \\
\hline 2012 & 138,185 & 449 & 3.91 \\
\hline
\end{tabular}

\section{Lakeland Area Mass Transit District}
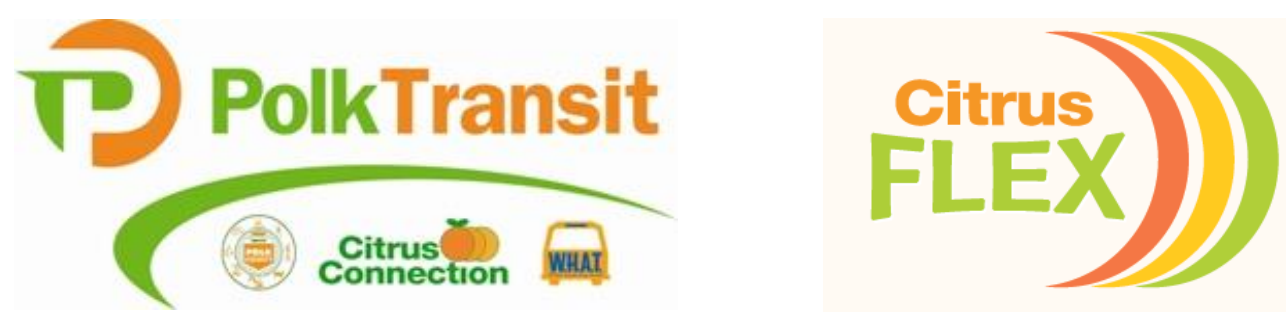

\section{Agency Name}

Lakeland Area Mass Transit District (Citrus Connection)

Polk Transit

\section{Agency Description}

The Lakeland Area Mass Transit District initiated services in the Lakeland, Florida area in December 1982. Operating as the Citrus Connection, the transit agency has expanded over the past three decades, with today's fleet of 38 buses and 15 Handy buses traveling more than 7,500 miles daily. Today the Citrus Connection picks up and delivers more than 6,000 people to work, play, school and other destinations every day. It provides specialized transportation for citizens who are unable to use regular service. According to the National Transit Database, Citrus Connection transported 1,558,035 passengers in FY 2011. 


\section{Flex Service Details}

In December 2012, Citrus Connection transitioned one of its underperforming fixed routes to flexible service. The new service type has been designated as "Citrus Flex," specifically the Route \#39 - Bradley Flex. This service model would be classified as a "route deviation route" where the buses operate on a fixed schedule with marked bus stops with the option for the bus to deviate off the route to serve demand-response requests within that route's service zone.

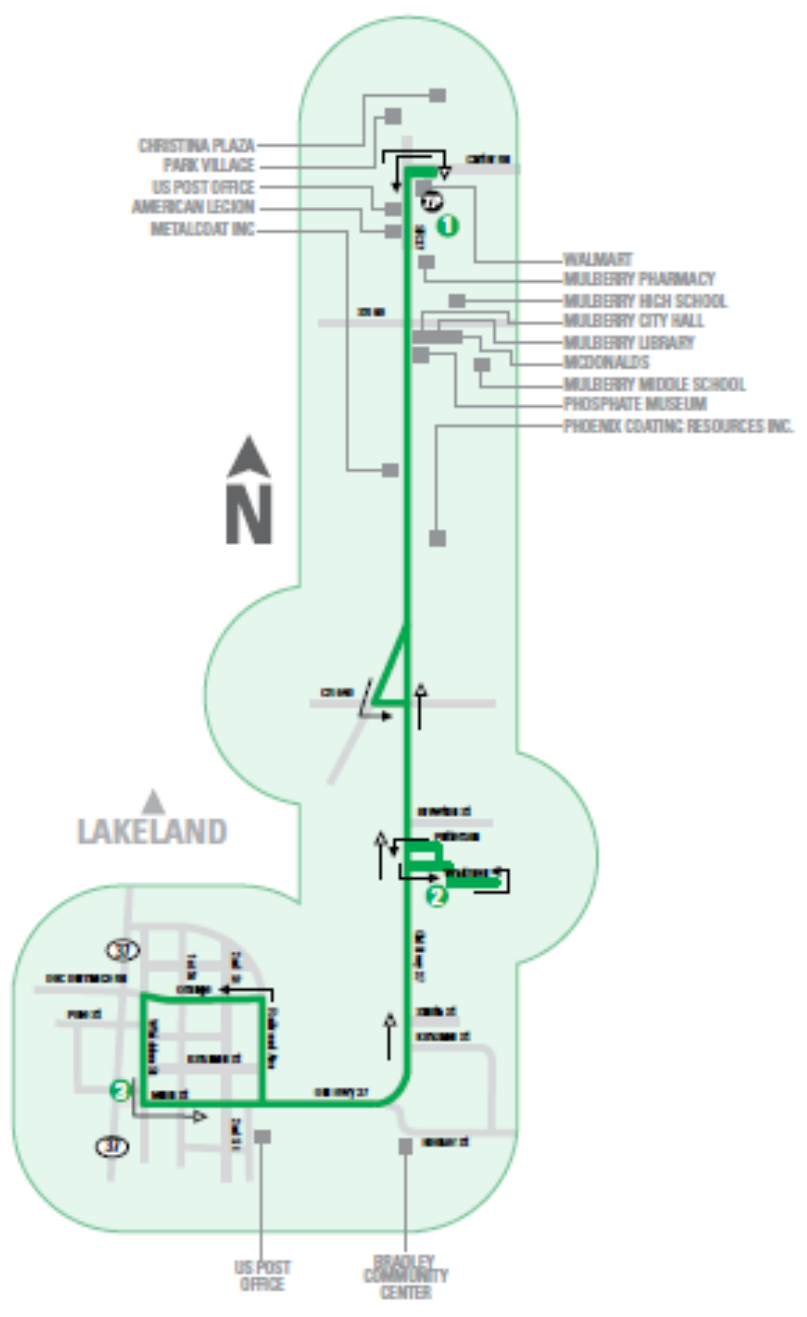

Figure 4-12

Bradley Flex Route 39

\section{Operations}

The new Citrus Flex provides regular scheduled service along a designated route from 6:00 a.m. to 5:00 p.m. from Monday to Friday, with service hours reduced to 8:00a.m. to 4:00pm on Saturdays. There is no Sunday service. 
Passengers can board the Citrus Flex at any designated bus stop. No flag stops are permitted. The service follows a set schedule with specific time points listed on the schedule. Reservations for walkup passengers are not required.

Route deviation service, within $3 / 4$ mile of the fixed route, is available upon advanced request. Requests must be made at least 24 hours in advance or up to two weeks in advance. Requests are honored on a first come - first served basis and are generally limited to two per trip.

The service is provided with smaller paratransit vehicles with a seating capacity of up to 10 passengers. The gasoline-powered buses can accommodate up to two wheelchair passengers.

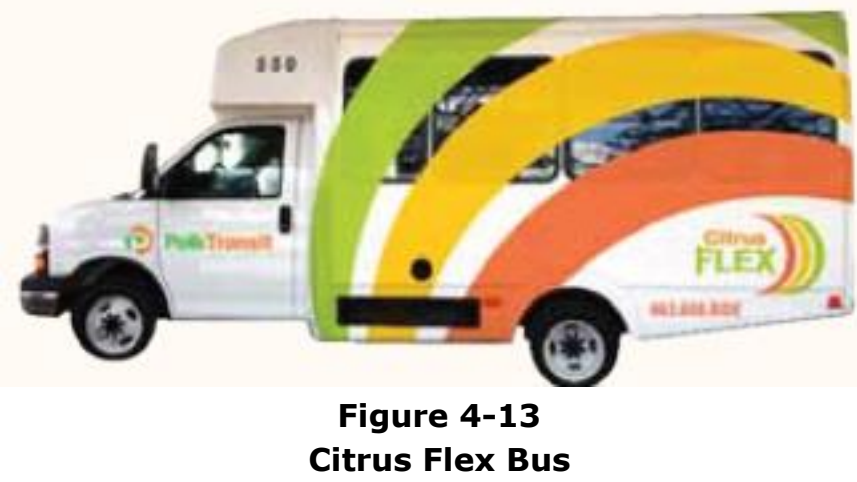

Citrus Flex fares are the same as the Citrus Connection fixed route service. Transfers to the connecting fixed route services require an additional bus fare. Regular passes are accepted on the flex services. The base adult fare is $\$ 1.50$, with one day passes available for $\$ 3$, weekly passes for $\$ 12$, and monthly passes at $\$ 47$. Senior citizens, persons with disabilities and youth ride for half fare.

Reservations are made through the Citrus Connection paratransit transit service system, and daily scheduling is handled by the Citrus Connection dispatchers. The Citrus Flex buses are equipped with Mobile Data Terminals (MTDs) and global positioning units. The scheduling and dispatching is supported by Trapeze software.

Eligible residents within the Flex Service zones remain eligible for the Citrus Connection complementary paratransit service, for both ADA service within and outside the zone.

The Citrus Flex Service is operated by the Citrus Connection bus operators.

\section{Outcomes}

Although still a new service, early ridership productivity has varied between monthly averages of 3 to 6 passengers per hour. The traditional fixed route the flex service replaced was averaging approximately 3 passengers per hour. The productivity improvements are 
credited in part to the ability of the route to access three mobile home parks previously not serviced.

The annual route cost savings for the conversion to the flex service are estimated to be $\$ 33,000$, contributed primarily to lower fuel and maintenance expenses.

\section{Pinellas Suncoast Transit Authority}

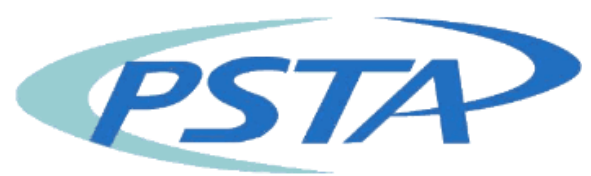

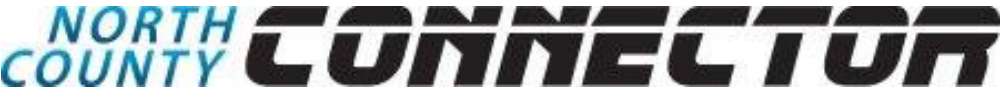

\section{Agency Name}

Pinellas Suncoast Transit Authority (PSTA)

\section{Agency Description}

The Pinellas Suncoast Transit Authority (PSTA) was created in 1984 with the merger of the St. Petersburg Municipal Transit System and the Central Pinellas Transit Authority and is the public transit provider in the county. PSTA began operations in 1984 with 128 buses providing service on 79 fixed routes

Today PSTA provides service throughout Pinellas County utilizing 199 vehicles operating on 40 fixed routes. According to the National Transit Database, PSTA transported 13,101,512 passengers in FY 2011.

\section{Flex Service Details}

In December 2012, PSTA introduced its flexible Connector service with three routes designed to serve the northern areas of Pinellas County.

The North County Connector Service is a flexible type of bus service that travels along a specific fixed corridor, but will deviate up to $3 / 4$ of a mile off that route to pick up passengers upon request within the designated zone. This service model would be defined as "route deviation" where the vehicles operate along a well-defined path, but are allowed to deviate off route to serve demand-responsive requests within a defined zone.

This flexible transit service provides improved mobility for people who do not live or work on a bus line. They act as feeder and distributor services to connect people with regular, PSTA fixed-route service. 
The three North County Connectors include the:

- East Lake Connector, which carries passengers from the Shoppes at Boot Ranch along East Lake Road to Tarpon Mall.

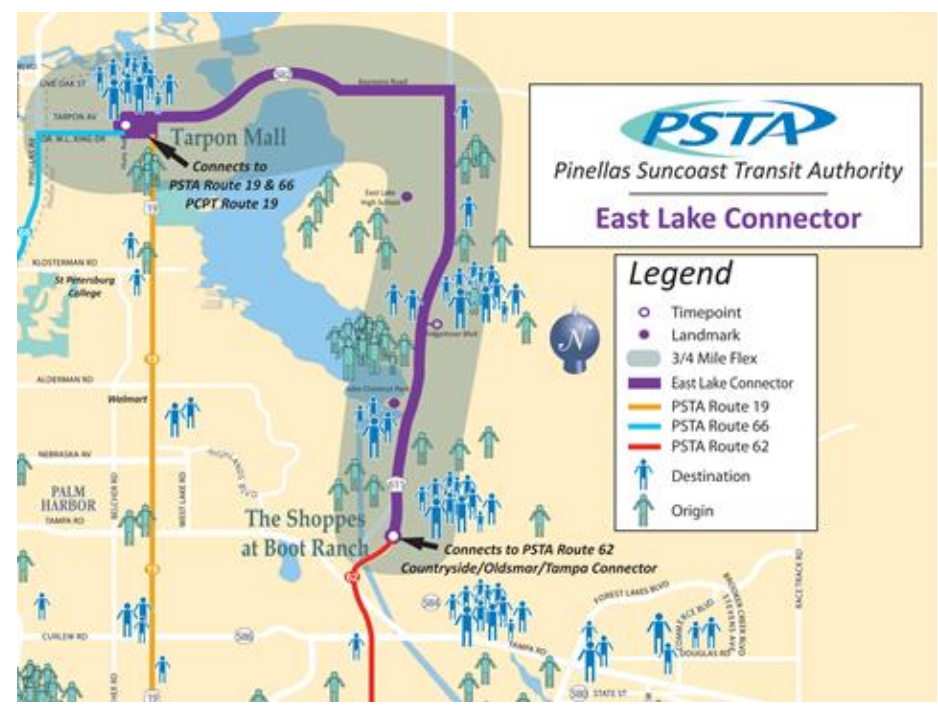

Figure 4-14

East Lake Connector

- Dunedin/Palm Harbor Connector, which travels from Westfield Countryside Mall into Dunedin along SR 580, north on CR1/Keene to Nebraska, and north on US 19 to the Palm Harbor Wal-Mart, including a few trips further north to serve the St. Pete College Tarpon Springs Campus.

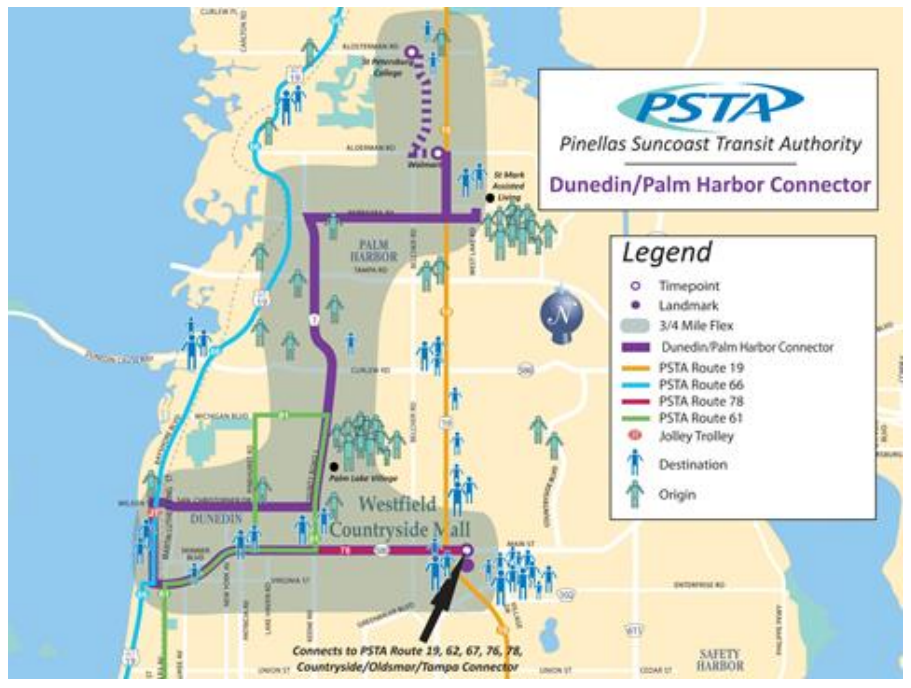

Figure 4-15

Countryside/Oldsmar/Tampa Connector 
- Countryside/Oldsmar/Tampa Connector, which travels east out of Westfield Countryside to Oldsmar where it travels on Hillsborough Avenue and into Tampa, serving HART's Northwest Transit Center.

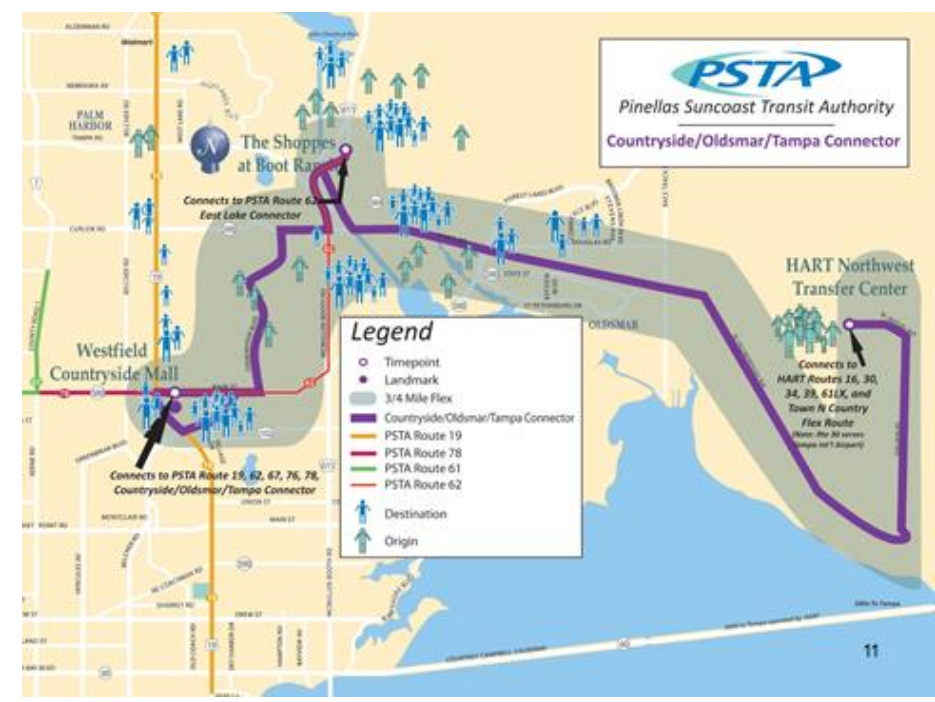

Figure 4-16

Dunedin/Palm Harbor Connector

All three North County Connector routes provide connections to major activity centers and several fixed routes, including routes operated by HART and Pasco County Transit. Additionally, all three North County Connector routes interlink with each other.

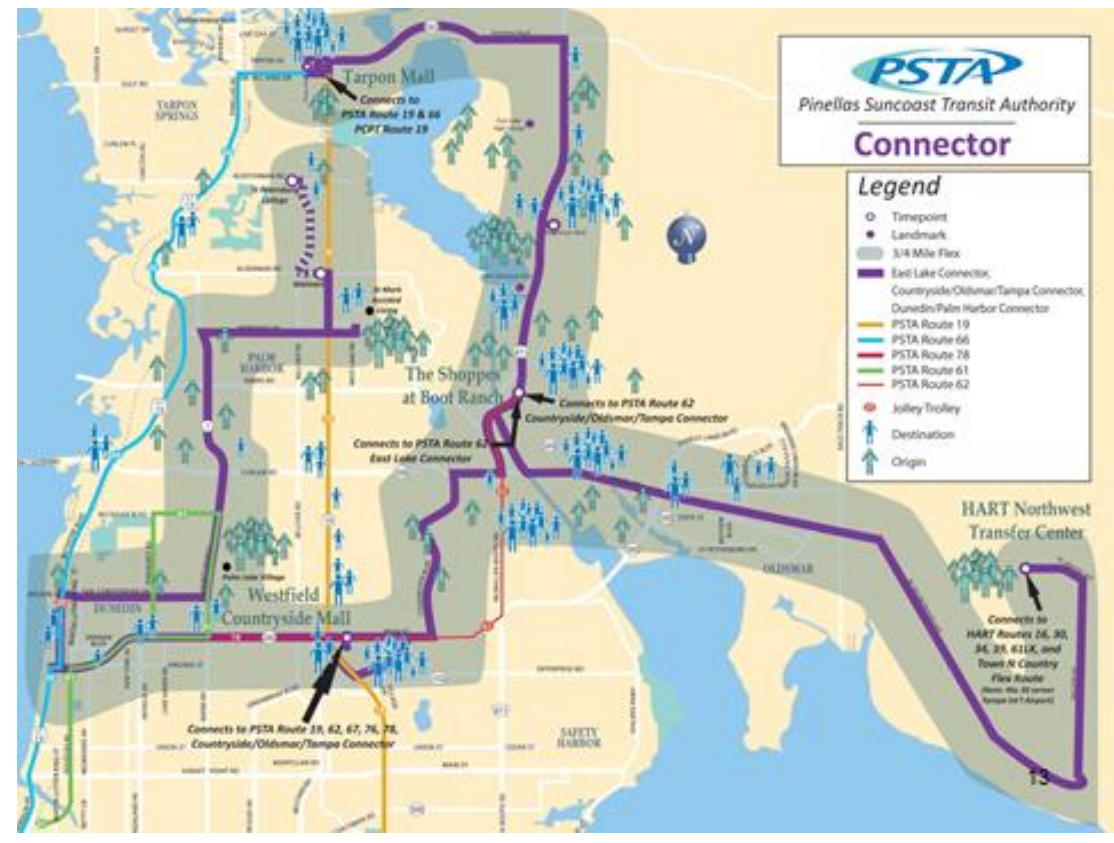

Figure 4-17

Combined North County Connector Routes 


\section{Operations}

There are two ways to access the North County Connectors. The buses follow a pre-set route, so passengers can board at any bus stop along the route. Flag stops at safe, nonstop sign locations are also permitted. The second option is to arrange for the Connector service to come to the person's origin or destination within the zone.

If a passenger wants to deviate off the pre-set route, they will need to call the PSTA Info Line and make a reservation at least two hours in advance or up to three days in advance. Due to schedule constraints, deviations are limited to two per trip. No subscription service is permitted.

The fares on the Connector Service are the same as the rest of PSTA's local system. Reduced fares are available for qualified riders with proper identification and multi-ride passes, called GO Cards, are also accepted.

These Connector routes operate from Monday through Saturday from approximately 8:00a.m. until 6:30pm There is no Connector Service on Sundays or on the following holidays: New Year's Day, July 4th, Labor Day, Thanksgiving, and Christmas.

PSTA uses Champion low floor cutaway buses that seat 14 passenger with one wheelchair, or 12 passengers with two wheelchair passengers. The PSTA Connector buses are all equipped with bike racks that can accommodate up to two bicycles, available on a first come - first served basis.

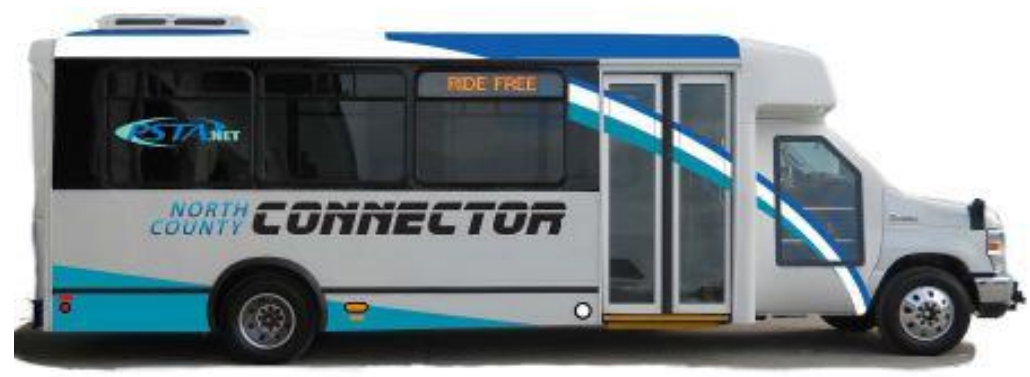

Figure 4-18

North Connector Bus

The PSTA Connector is supported with GFI fareboxes, Clever Devices, mobile data terminal units, and customized software. Route Match software will be implemented in the summer of 2013. A dedicated position schedules and dispatches the Connector buses.

PSTA Connector buses are operated by regular PSTA bus operators. 


\section{Outcomes}

Although only six months in operations, as detailed in Table 4-4, the North County Connectors have steady progress with increasing ridership. Table 4-5 summarizes the reservation history by route for the same time period.

Table 4-4

North County Connector Ridership

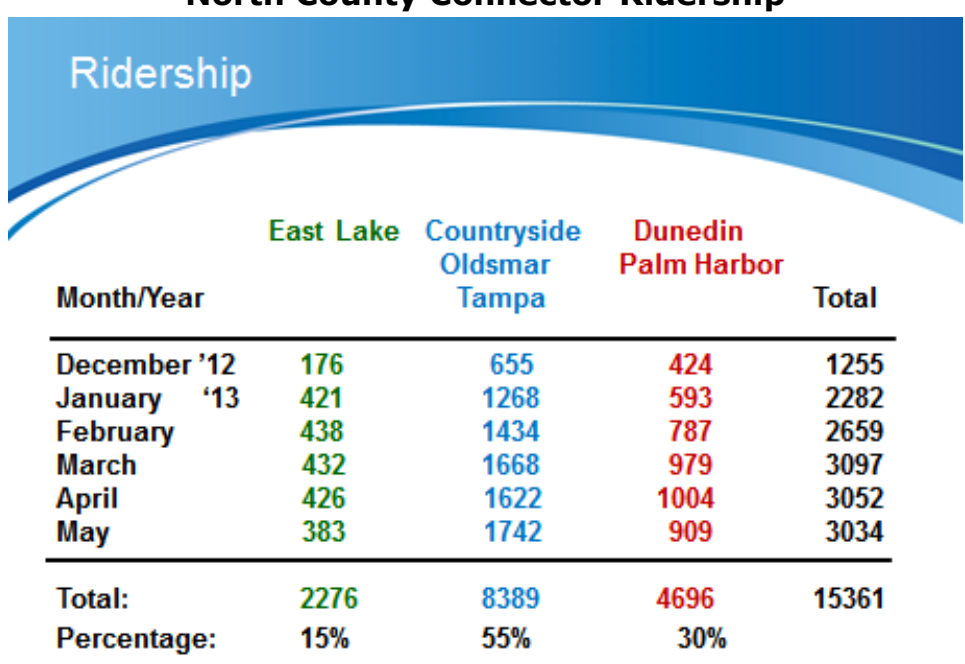

Table 4-5

North County Connector Reservations

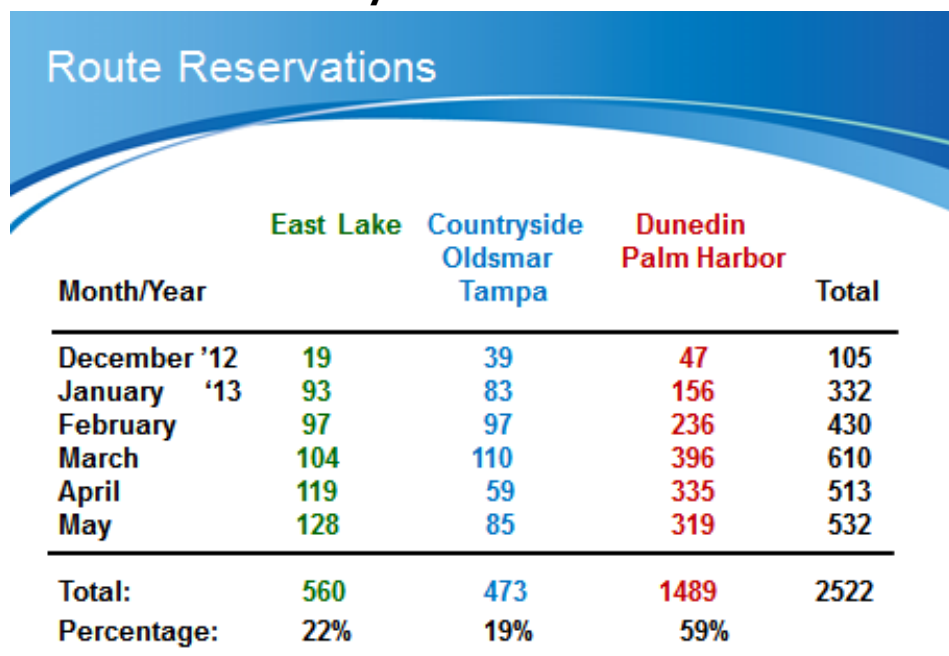




\section{Volusia County Transit}

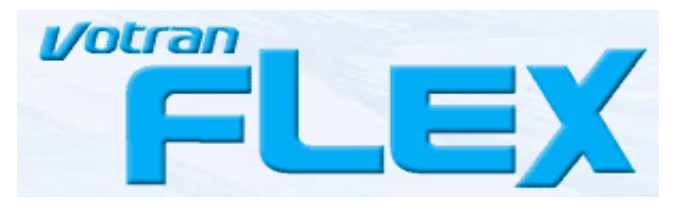

\section{Agency Name}

Volusia County Transit (Votran)

\section{Agency Description}

Votran, Volusia County's public transportation system, was established in 1975 by Volusia County Government. Votran provides transportation to all urban areas of the county with a fleet of 55 fixed route buses, four trackless trolleys and 44 paratransit vehicles. Additional services are provided through contracted providers. Votran's staff has grown to more than 200 employees.

According to the National Transit Database, Votran transported 3,857,158 passengers in FY 2011.

\section{Flex Service Details}

Since October 2010, Votran has operated two "point deviation routes" in the New Smyrna Beach area in south Volusia County. These routes are marketed as Votran Flex routes. The two routes which operate in a coordinated manner are Route \#42 Flex Beachside and Route \#43 Flex Mainland. These two flex routes replaced existing fixed route services that were experiencing low productivity and ridership. The Votran Flex services are open to the general public.

As detailed in the route map graphic (Figure 4-19), each route operates as a demand response service with limited designated stops within their respective service zones. The two Flex routes connect with each other hourly at the Canal Street/Sams Avenue transfer center. Additionally, both Flex routes connect hourly with two Votran fixed route buses at U.S. 42 and Canal Street. Votran Route \#40 - Port Orange makes the connections to points north of New Smyrna Beach and Votran Route \#41 - Edgewood which serves areas south of New Smyrna Beach.

\section{Operations}

Both Votran Flex routes operate on hourly headways with a service span from 6:45 a.m. to 6:45 p.m. from Monday through Saturday. There is no Sunday or holiday service.

With the exception of three designated stops per route, the Votran Flex Service operates as demand response service providing curb to curb, flexible transit service to any location 
within the designated service area. Reservations must be made at least two hours in advance of the planned travel. Reservations may be made up to three days in advance. For recurring trips (i.e., trips to and from the same locations on the same day of the week), a subscription or standing order can be placed. No flag stops are permitted within the designated service areas.

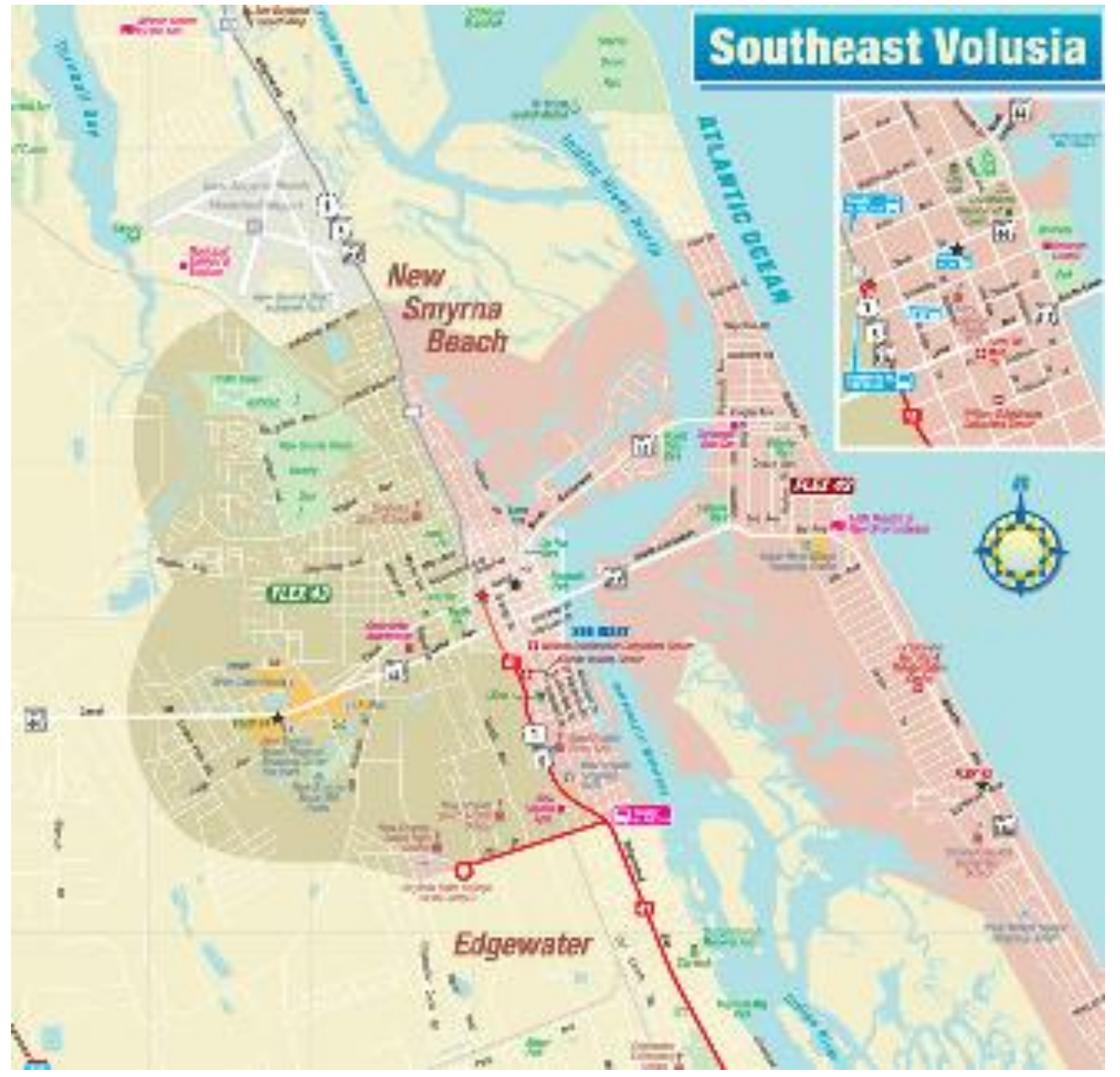

Figure 4-19

Route \#42 Flex Beachside and Route \#43 Flex Mainland

The service is provided with smaller paratransit vehicles with a seating capacity of up to 18 passengers. The buses can accommodate up to two wheelchair passengers. No standee passengers are permitted on the Flex buses. All buses are equipped with bicycle racks that can handle two bicycles.

Flex Service fares are the same as those for Votran fixed route service. Transfers between the two flex routes are free, but transfers between flex and fixed route services require an additional bus fare. Regular Votran passes are accepted on the flex services. The base adult fare is $\$ 1.25$, with one day passes available for $\$ 3$, three days passes for $\$ 6$, seven 
day passes for $\$ 12$, and monthly passes at $\$ 40$. Senior citizens, persons with disabilities, and youth ride for half fare.

Reservations are made through the Votran paratransit service system and daily scheduling is handled by Votran dispatchers. The Votran Flex Service buses are equipped with Mobile Data Terminals (MTDs) and Garmin global positioning units. The scheduling and dispatching is supported by Trapeze software.

Eligible residents within the Flex Service zones remain eligible for the Votran complementary paratransit service, for both ADA service within and outside the zone.

The Votran Flex Service is operated by Votran paratransit bus operators.

\section{Outcomes}

The combined Votran Flex Services, now in the third year of operation, have experienced an 8.2 percent growth from FY 2011 to FY 2012, growing from 19,300 annual trips to 20,875 trips. For the first five months of FY 2013, monthly passengers per hour statistics have ranged from 2.04 to 2.57 .

Cost comparisons between the Votran Flex Services and Fixed Route reveal a 30.3 percent savings in cost per hour and a 38.8 percent savings in cost per mile.

Table 4-6

Votran Flex Services and Fixed Route Cost Comparisons

\begin{tabular}{|l|l|l|l|l|}
\hline & \multicolumn{1}{l}{$\begin{array}{l}\text { Flex } \\
\text { Service }\end{array}$} & \multicolumn{1}{l}{$\begin{array}{l}\text { Fixed } \\
\text { Route }\end{array}$} & Savings & Percent \\
\hline $\begin{array}{l}\text { Cost per } \\
\text { Hour }\end{array}$ & $\$ 36.59$ & $\$ 52.47$ & $\$ 15.88$ & $30.3 \%$ \\
\hline $\begin{array}{l}\text { Cost per } \\
\text { Mile }\end{array}$ & $\$ 2.49$ & $\$ 4.07$ & $\$ 1.58$ & $38.8 \%$ \\
\hline
\end{tabular}




\section{Chapter 5 Summary}

This synthesis project has identified numerous examples of the United States public transit industry embracing non-traditional service delivery models. As demand increases for public transportation services that meet the mobility need of diverse markets and environments, the transit industry has begun to deploy flexible transportation services. These nontraditional service delivery models have proven to be more cost effective in providing services to areas with low or irregular demand, including suburban, small urban, and rural markets.

The transit industry, through research such as this report and recent TCRP efforts, has provided some structured definitions to a variety of flexible transportation services, including these six basic service models: route deviation, point deviation, demandresponsive connector, request stops, flexible-route segments, and zone routes.

Among the motivations for moving toward greater use of flexible services are the reductions of expenses, improving existing transit service, serving low density areas, serving special needs populations, and reducing the need for traditional paratransit services.

Flexible transit services within Florida were originated within the past decade (i.e., JTA in the mid-2000s, followed by LYNX in 2007) with the addition of other flexible services in 2010 (i.e., Votran in 2010, and HART in 2010 and 2011). The most recent Florida flexible transit services were introduced in December 2012 (i.e., PSTA and Citrus Connection). All of these services appear to be well established and well received, with all six transit agencies exploring additional expansion of flexible transit routes.

Flexible transit routes have allowed these Florida transit agencies to replace underperforming fixed routes and expand transit service to non-traditional, low density service areas. The use of smaller buses has improved access to neighborhoods that were inaccessible to larger transit buses. In all cases, the Florida transit agencies have used their flexible routes to provide feeder service to their fixed route networks.

The use of flexible transit services in Florida is now well established and continues to evolve. Multiple service options and alternatives have been employed, with each tailored to fit local need and operating policies. Flexible transit services recently introduced appear to be well received by the public and interest for additional flexible services is strong. The following section provides a list of topics that transit agencies should explore when considering whether to add flexible services to their family of services. 


\section{Planning Considerations for Flexible Transit Services}

The following section provides a list of topics that transit agencies should explore when considering whether to add flexible services to their family of services. Some common "rules of thumb" for flexible services are included.

\section{Project Justification}

As detailed previously in the report, there are numerous motivations and expectations to consider when planning and implementing flexible transit services. The transit agency should define the primary purpose of the new service, which will in turn help define the operating parameters and performance measures.

Motivations for the flexible service projects could include, but would not be limited to:

- Providing service to spread-out, low density areas

- Establishing the foundation for future fixed route service

- Responding to challenging service area limitations (e.g., narrow streets, lack of sidewalks, poor street network, and geography)

- $\quad$ Serving special population groups (e.g., seniors)

- Reducing the demand on other paratransit services

- Reducing operating expenses (e.g., lower labor rates, increased fuel efficiency, and lower vehicle maintenance costs)

\section{Type of Flex Service}

Chapter Three provided definitions and explanations of the typical flexible service types. Based on the project motivation and expectations, the structure of the new flexible service must be detailed. For example, demand response service may be most appropriate for large, low density service areas. On the other hand, some form of route deviation may be more appropriate in areas in which traditional fixed routes structure is appropriate.

Another critical factor in this service type selection decision would be the connections or transfer opportunities with other fixed routes within the transit system. The location of the passenger transfers and their frequency will have direct impact on the type and design of the flexible service selected.

\section{Designation of the Flex Zone}

The designation of the area (or zone) served by the flexible service is another key decision that must be made early in the planning process. If the service area is too large, keeping the service on schedule and connecting with the fixed route buses will prove to be difficult. Additionally, a large area may limit the number of route deviations that can be undertaken. The Florida case studies operators' advice was to limit the flexible service zones to 5 to 7 square miles. 


\section{Coordination with System}

In conjunction with the previous two topics, connecting the flexible route with the fixed route service is an important design feature and will result in higher usage of the flexible service. This allows the flexible service to act a collector system for the fixed route system.

\section{Flex Service Impact and Expectations on ADA Complementary Paratransit}

One of the possible motivations for implementing flexible transit services to areas currently served by the fixed route service is the potential to reduce the demand on the transit systems Complementary ADA paratransit service.

It should be noted, however, that all of the Florida case studies still provided their Complementary ADA paratransit services in the areas served by the flexible routes.

\section{Service Design}

In addition to defining the type of flexible service option and the flexible service area, there are several decisions that need to made, including:

- If applicable, how the bus stops are designated for the fixed route portion of the service - bus stop sign, flag stop, or other

- The span of service hours per day

- The days of the week the service is offered

- The required advance notice to reserve a route deviation or pick-up

- Guidelines for route deviations:

- Number of deviations per trip allowed

- Distance of an allowable deviation (i.e., linked to definition of service area)

- Defining where route deviations should reenter the route

- Transfer time allowed for connections with fixed route services

\section{Fare Policy}

A decision on what to charge for the flexible transit services is another critical decision that must be made. One approach is to offer fare incentives to encourage use of the flexible service through lower fares or free transfers to the fixed route system. The other approach is to treat the flexible service as an equal with other transit services provided by the transit agency. This allows for a more simplified fare structure and a more completed integration of the flexible transit service into the transit agency's family of services.

For the six Florida case studies, only HART offered a discounted fare for their flexible services and only LYNX provided a free transfer between the flexible service and the fixed service routes.

The prevailing Florida approach was to view the flexible transit service as one the agency's service options and to employ the system's base fare for the flexible service. Furthermore 
with the use of electronic fare collection systems and a variety of pass options (e.g., daily, weekly and monthly), most systems have eliminated using transfers and charge transferring passengers with another fare.

\section{Vehicle Types}

The type and size of vehicles used for flexible service is another key decision that must be reached. The availability of the selected bus will impact the decision on the initiation of service. Smaller cutaway buses seem to be the prevalent choice due to their ability to accommodate the lower passenger loads and ability to maneuver on local streets. The smaller buses also provide lower purchase costs, more fuel efficiency, and lower maintenance expenses.

As detailed in the case studies, the typical vehicle used in the Florida flexible service are 23foot in length, with wheelchair accessibility, and able to accommodate 12-18 passengers.

\section{Scheduling and Dispatch}

As part of the operational design of the service, decisions must be made as to how and where in the organization to handle the ride request reservations and scheduling. The general approach is locating these functions within the other paratransit operations.

The Florida case studies operators' advice was provide a dedicate position to handle these duties if multiple flexible services are offered.

\section{Technology}

The utilization of technology is important for efficient operations. In all Florida cases, the flexible service vehicles were equipped automatic vehicle locator systems and mobile data units. Similarly, the reservations and scheduling functions were supported by the agencies other paratransit scheduling software system. Technology is important to manage the flexible services in a cost efficient and effective manner.

\section{Service Goals, Objectives \& Performance Measures}

When developing the project justification and motivations, realistic service goals, objectives and performance measures should be developed. It is important to set realistic expectations of the application of flexible services.

Depending on the specific design and type of the flexible service, expected productivity will probably not exceed 6 to 8 passengers per hour. 


\section{Appendix A}

\section{Survey Instrument}




\section{Survey Instrument}

\section{Flexible Public Transportation Services in Florida}

\section{Survey Questions}

\section{BACKGROUND}

Due to the increasing demand to provide public transportation services and meet the mobility need of diverse markets and environments, the transit industry has designed flexible transportation service delivery methods. These unconventional service delivery models have proven to be a more cost effective method to meeting these demand challenges. They also show great promise in addressing Americans with Disabilities Act (ADA) complementary paratransit service requirements, as well as providing services to areas with low or irregular demand, including suburban, small urban, and rural markets. Flexible transportation services include, but are not limited to, route and point deviations, demandresponse connectors to standard fixed route services, by request or "flag" stops, and flexible segments or zone routes.

The Florida Department of Transportation (FDOT) has great interest in exploring the current application and future potential for the implementation of flexible transportation services to meet the mobility needs of Florida residents who reside in non-traditional transit areas and visitors to those areas. FDOT has contracted with the National Center for Transit Research at the USF Center for Urban Transportation Research (CUTR) to undertake this research effort.

\section{PURPOSE}

This brief survey is being directed to Florida's public transportation agencies with the purpose of determining to what extend flexible services are currently being utilized within Florida. All that is required is to inform us if your transit agency has implemented any "flexible services" in the past five years and then to provide us with a contact person within you organization with which we can follow up to get the details and specifics.

\section{DEFININTIONS OF FLEXIBLE SERVICE TYPES}

For the purposes of this survey, the concept of flexible public transportation services includes the following:

- Route Deviation-vehicles operating on a regular schedule along a well-defined path, with or without marked bus stops that deviate to serve demand-responsive requests within a zone around the path. The width or extent of the zone may be precisely established or flexible.

- Point Deviation-vehicles serving demand-responsive requests within a zone and also serving a limited number of stops within the zone without any regular path between the stops.

- Demand-Responsive Connector-vehicles operating in demand-responsive mode within a zone, with one or more scheduled transfer points that connect with a fixed-route network. A high percentage of ridership consists of trips to or from the transfer points.

- Request Stops-vehicles operating in conventional fixed-route, fixed-schedule mode and also serving a limited number of undefined stops along the route in response to passenger requests.

- Flexible-Route Segments-vehicles operating in conventional fixed-route, fixed-schedule mode, but switching to demand-responsive operation for a limited portion of the route.

- Zone Route-vehicles operating in demand-responsive mode along a corridor with established departure and arrival times at one or more end points in the zone

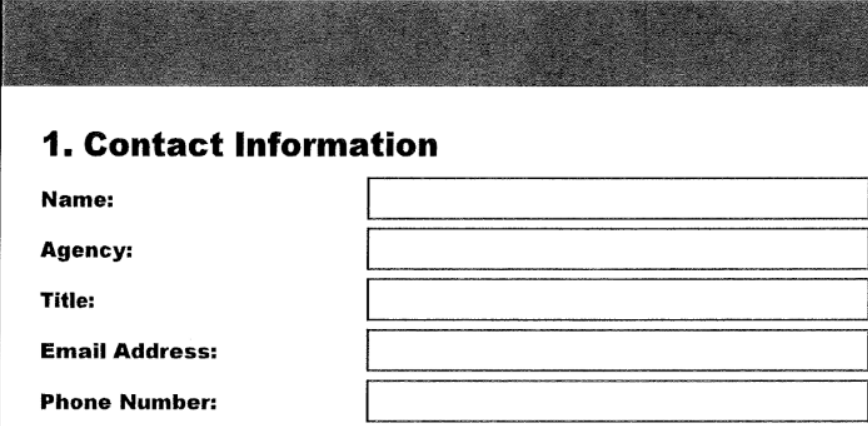

Phone Number: 


\section{Flexible Public Transportation Services in Florida}

2. Based upon the definitions of flexible service previously provided, has your agency operated any flexible services within the past five (5) years?

$\bigcirc$ Yes

No

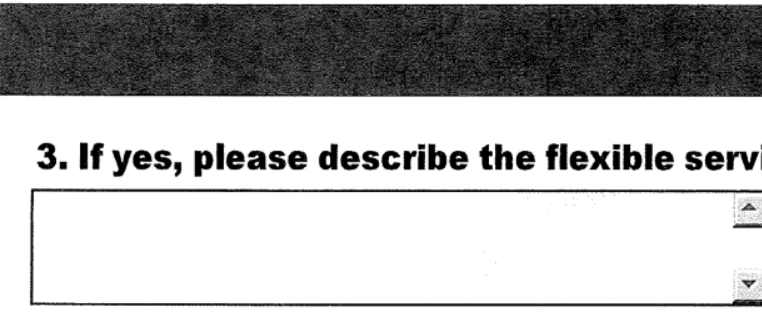

4. If yes, please provide us with the staff person within your organization who we should contact for further information on your agency's flexible services.

Staff Name:

Staff Title:

Staff Email Address:

Staff Phone Number:

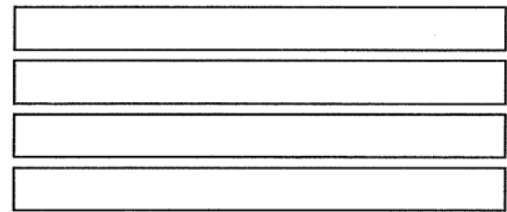




\section{References}

${ }^{1}$ Teal, Roger F., and Becker, A. Jeff, "Business Strategies and Technology for Access by Transit in Lower Density Environments, " Research in Transportation Business \& Management, 2011.

${ }^{2}$ Ibid.

${ }^{3}$ Ibid.

${ }^{4}$ University Transportation Center for Mobility, "Examining Challenges Opportunities and Best Practices for Addressing Rural Mobility and Economic Development under SAFETEALU's Coordinated Planning and Human Services Framework", 2010.

${ }^{5}$ Potts, John F., Marshall, Maxine A., Crockett Emmett C., and Washington, Joel, "TCRP Report 140: A Guide for Planning and Operating Flexible Public Transportation Services", Transit Cooperative Research Program, Transportation Research Board, The National Academies, Washington, D.C., 2010.

6 Ibid.

7 Ibid.

${ }^{8}$ Weiner, Richard, "TCRP Synthesis Report 76: Integration of Paratransit and Fixed-Route Transit Services - A Synthesis of Practice", Transit Cooperative Research Program, Transportation Research Board, The National Academies, Washington, D.C., 2008.

${ }^{9}$ Ibid.

${ }^{10}$ TranSystems Corporation, RLS \& Associates, and Nelson\Nygaard Consulting, "Transportations Services for People with Disabilities in Rural Small Urban Communities", Easter Seals, Project Action, Washington, D.C., 2006.

${ }^{11}$ Ibid.

12 Ibid.

13 Koffman, D., "TCRP Synthesis 53: Operational Experiences with Flexible Transit Services", Transit Cooperative Research Program, Transportation Research Board, The National Academies, Washington, D.C., 2004.

14 Ibid.

15 Ibid.

${ }^{16}$ Ibid. 